\title{
Acetylcholine Becomes the Major Excitatory Neurotransmitter in the Hypothalamus In Vitro in the Absence of Glutamate Excitation
}

\author{
Andrei B. Belousov, ${ }^{1}$ Bruce F. O'Hara, ${ }^{2}$ and Janna V. Denisova ${ }^{1}$ \\ ${ }^{1}$ Department of Cell and Molecular Biology, Tulane University, New Orleans, Louisiana 70118, and 2Department of \\ Biological Sciences, Stanford University, Stanford, California 94305
}

Glutamate and GABA are two major fast neurotransmitters (excitatory and inhibitory, respectively) in the CNS, including the hypothalamus. They play a key role in the control of excitation/ inhibition balance and determine the activity and excitability of neurons in many neuronal circuits. Using neuronal cultures, whole-cell recording, $\mathrm{Ca}^{2+}$ imaging, and Northern blots, we studied the compensatory regulation of neuronal activity during a prolonged decrease in glutamate excitation. We report here that after a chronic (6-17 d) blockade of ionotropic glutamate receptors, neurons in hypothalamic cultures revealed excitatory electrical and $\mathrm{Ca}^{2+}$ synaptic activity, which was not elicited in the control cultures that were not subjected to glutamate blockade. This activity was suppressed with acetylcholine (ACh) receptor antagonists and was potentiated by eserine, an inhibitor of acetylcholinesterase, suggesting its cholinergic nature. The upregulation of $\mathrm{ACh}$ receptors and the contribution of $\mathrm{ACh}$

Synaptic excitation/inhibition imbalance may occur in neuronal circuits under normal conditions such as during an increase or decrease in activity of glutamate excitatory or GABA inhibitory inputs to neurons during development. It may also occur under pathological conditions (e.g., during the degeneration of glutamate or GABA neurons and terminals) or under conditions of pharmacological blockade of glutamate or GABA receptors used for clinical purposes. Such imbalance between the excitation and inhibition may change the activity and excitability of neurons in a circuit or may also disturb circuit function and viability. It has been known for many years that a relative increase in glutamate excitation or decrease in GABA inhibition in slices or cultures obtained from different regions of the CNS lead to glutamatedependent neuronal hyperexcitability, which, if sustained, causes cell death (Mody et al., 1992; Choi, 1994; Thompson et al., 1996). In contrast, a decrease in glutamate-mediated excitation usually leads to the immediate domination of GABA inhibition (Bradford, 1995; Belousov and van den Pol, 1997b). Because GABA is not as toxic to neurons as glutamate, neurons in cultures can survive in the absence of glutamate excitation and the presence of GABA inhibition for long periods of time (up to several months)

Received June 18, 2000; revised Dec. 20, 2000; accepted Jan. 4, 2001.

This research was supported by Tulane University funds (A.B.B.), Board of Regents Support Fund (A.B.B.), and National Institutes of Health Grant DA00187 (B.F.O.). We thank Dr. Anthony N. van den Pol and Dr. Hilary Srere for helpful discussions in the early phases of this project, and Steve Wiler and Vinh Cao for technical support.

Correspondence should be addressed to Dr. Andrei B. Belousov, Department of Cell and Molecular Biology, 2000 Percival Stern Hall, Tulane University, New Orleans, LA 70118. E-mail: belousov@tulane.edu.

Copyright (C) 2001 Society for Neuroscience 0270-6474/01/212015-13\$15.00/0 to the control of the excitation/inhibition balance in cultures after a prolonged decrease in glutamate activity were also demonstrated. Enhanced ACh transmission was also found in chronically blocked cerebellar but not cortical cultures, suggesting the region-specific character of glutamate-ACh interactions in the brain. We believe that in the absence of glutamate excitation in the hypothalamus in vitro, $\mathrm{ACh}$, a neurotransmitter normally exhibiting only weak activity in the hypothalamus, becomes the major excitatory neurotransmitter and supports the excitation/inhibition balance. The increase in excitatory ACh transmission during a decrease in glutamate excitation may represent a novel form of neuronal plasticity that regulates activity and excitability of neurons during the glutamate/GABA imbalance.

Key words: acetylcholine; glutamate; GABA; hypothalamus; plasticity; excitation/inhibition balance
(Furshpan and Potter, 1989; Belousov and van den Pol, 1997a,b). However, the mechanisms that regulate activity and excitability of neurons during the prolonged decrease in glutamate excitation were not studied. It is not known whether such long-term imbalance between glutamate excitation and GABA inhibition can affect neuronal properties and functions and whether during this imbalance any compensatory mechanisms can be expressed by neurons to reestablish more normal synaptic excitation/inhibition interactions.

The hypothalamus is the crucial part of the brain that regulates homeostasis throughout the body. It contains $>20$ active substances that could be released synaptically within this brain structure, including acetylcholine (ACh), dopamine, and several other neurotransmitters and neurohormones. Glutamate and GABA neurons and receptors are also distributed within the hypothalamus, where they control the release of neurohormones, circadian activity, and other hypothalamic functions (van den Pol et al., 1990, 1994; Meeker et al., 1994; Belousov and van den Pol, 1997b; Obrietan and van den Pol, 1998). In the present set of experiments, we used primary hypothalamic neuronal cultures to study the mechanisms of compensatory regulation of neuronal activity during a prolonged blockade of ionotropic glutamate receptors. When we examined neuronal characteristics in cultured neurons, we found a dramatic upregulation of excitatory ACh transmission after a long-term decrease in glutamate activity. Additionally, neuronal disinhibition with $\mathrm{GABA}_{\mathrm{A}}$ receptor antagonists revealed excitotoxic effects of synaptically released $\mathrm{ACh}$ in cultures after a chronic glutamate receptor blockade but not in the control cultures that were not subjected to the blockade of glutamate neurotransmission. Together, our data suggest that during a long- 
term decrease in the glutamate-mediated excitation in hypothalamic cultures, another less predominant excitatory neurotransmitter, ACh, begins to play the role of the major excitatory neurotransmitter and to support the excitation/inhibition balance in these cultures.

\section{MATERIALS AND METHODS}

Tissue cultures. Neuronal cultures were prepared from the embryonic (day 18-19) medial hypothalamus, cerebellum, and cortex obtained from Sprague Dawley rats as described (Belousov and van den Pol, 1997a). To obtain embryonic tissue, a pregnant rat was anesthetized with Nembutal $(70 \mathrm{mg} / \mathrm{kg}$ ) before embryos were removed. The tissue was then treated enzymatically ( $10 \mathrm{U} / \mathrm{ml}$ papain, $500 \mu \mathrm{M}$ EDTA, $1.5 \mathrm{mM} \mathrm{CaCl}_{2}, 0.2 \mathrm{mg} / \mathrm{ml}$ L-cysteine in Earle's balanced salt solution) for $30 \mathrm{~min}$, resuspended in standard tissue culture medium, and triturated to form a single-cell suspension. The suspension was plated onto 22 -mm-square glass coverslips precoated with polylysine (540,000 Da; Sigma-RBI; St. Louis, MO). Cultures were maintained in a Napco 5430 incubator at $37^{\circ} \mathrm{C}$ with $5 \%$ $\mathrm{CO}_{2}$. Cells were raised in glutamate- and glutamine-free minimal essential medium (Life Technologies, Rockville, MD) supplemented with 10\% fetal bovine serum, $5 \mathrm{mg} / 100 \mathrm{ml}$ gentamicin, and $6 \mathrm{gm} / 1$ glucose. After $2 \mathrm{~d}$ in vitro (DIV), the proliferation of non-neuronal cells was inhibited by the application of cytosine $\beta$-D-arabinofuranoside $(1 \mu \mathrm{M})$. Two groups of cultures were used in most experiments: (1) cultures subjected to a chronic (14-17 d) blockade of NMDA and non-NMDA (AMPA and kainate) ionotropic glutamate receptors with D,L-2-amino-5-phosphonovalerate (AP5; $100 \mu \mathrm{M}$ ) and 6-cyano-7-nitroquinoxaline-2,3-dione (CNQX; $10 \mu \mathrm{M}$ ) ("blocked cultures") and (2) sister control cultures not subjected to a glutamate receptor blockade. In most experiments, AP5 and CNQX were added to the incubation medium of the first group of cultures beginning 4 DIV, and neurons were tested after 14-17 $\mathrm{d}$ in block (DIB). Some cultures were chronically incubated in the presence of other receptor antagonists or $20 \mathrm{~mm} \mathrm{KCl}$ as described in the text. Tissue culture medium was changed twice a week. Only healthy looking cultures were used in experiments; unhealthy cultures were discarded.

Electrophysiology. Standard bathing solution contained (in mM): 158.5 $\mathrm{NaCl}, 2.5 \mathrm{KCl}, 2 \mathrm{CaCl}_{2}, 10 \mathrm{HEPES}, 10$ glucose, and $1 \times 10^{-3}$ glycine, $\mathrm{pH} 7.3,325$ mOsm (room temperature, $20-22^{\circ} \mathrm{C}$ ). To perfuse the cells with solutions containing different agonists and antagonists for receptors, a flow pipe perfusion system was used (Belousov and van den Pol, 1997a). It consisted of several inputs into a final single short output terminated by a $0.5 \mathrm{~mm}$ internal diameter glass pipette. This perfusion pipette was aimed at the recorded cells $(100 \mu \mathrm{m}$ away), which were perfused continuously with the flow rate of $1.5 \mathrm{ml} / \mathrm{min}$ from the source containing the incubating solution. To change from one solution to another, the flow of the first solution was stopped, and the flow of the second solution was started. The newly applied solution flooded the tested cell in $<0.5 \mathrm{sec}$.

The whole-cell current-clamp or voltage-clamp recordings were made with an Axoclamp-2B amplifier (Axon Instruments, Foster City, CA). Glass pipettes were pulled from borosilicate glass capillaries of $2 \mathrm{~mm}$ diameter and $0.2 \mathrm{~mm}$ wall thickness and filled with an internal solution that included (in $\mathrm{mM}$ ): 145 potassium methylsulfate, 10 HEPES, 5 $\mathrm{MgCl}_{2}, 1.1$ EGTA, 4 Na-ATP, 0.5 Na-GTP, pH 7.2, 310 mOsm. After they were filled, the electrodes had a resistance of 2-5 M 2 . The seal resistances were 8-10 G $\Omega$. Single-electrode continuous voltage-clamp mode was used to measure the membrane input resistance $\left(R_{\text {input }}\right)$ and the activity of IPSCs as described (Belousov and van den Pol, 1997a). $R_{\text {input }}$ was measured using an application of negative square-wave voltage steps of $10 \mathrm{mV}$ amplitude (in the range of $10-50 \mathrm{mV}$ ) from a holding potential of $-60 \mathrm{mV}$. IPSCs were recorded at a holding potential of -30 $\mathrm{mV}$ in the presence of AP5 $(100 \mu \mathrm{M})$ and CNQX $(10 \mu \mathrm{M})$. Data were monitored using a Dell Pentium II XPS R400 MHz computer and pCLAMP7/DigiPack 1200-1 software (Axon Instruments) and analyzed off-line with Igor Pro (WaveMetrics, Lake Oswego, OR) and InStat software (GraphPad Software, San Diego, CA).

Fura-2 $\mathrm{Ca}^{2+}$ digital imaging. Cells were loaded for $30 \mathrm{~min}$ at $37^{\circ} \mathrm{C}$ with $5 \mu \mathrm{M}$ fura-2 acetoxymethyl ester (Molecular Probes, Eugene, OR) in a standard perfusion solution containing (in $\mathrm{mm}$ ): $137 \mathrm{NaCl}, 25$ glucose, 10 HEPES, $5 \mathrm{KCl}, 1 \mathrm{MgCl}_{2}, 3 \mathrm{CaCl}_{2}, 1 \times 10^{-3}$ glycine, $\mathrm{pH} 7.4$. In the case of chronically blocked cultures, AP5 $(100 \mu \mathrm{M})$ and CNQX $(10 \mu \mathrm{M})$ were added to the loading solution. The coverslip then was washed in a perfusion solution and held in a laminar style chamber (Warner Instrument Corporation, Hamden, CT) that allows for a rapid (5-10 sec) and complete change in the medium. Experiments were performed at room temperature $\left(20-22^{\circ} \mathrm{C}\right)$ and at a constant perfusion rate of $1.5 \mathrm{ml} / \mathrm{min}$. Cells were imaged on a Nikon inverted microscope with a Nikon Super Fluor $20 \times$ objective. Convention dual wavelength ratios were obtained during sequential recordings at 340 and $380 \mathrm{~nm}$ excitation. Switching between 340 and $380 \mathrm{~nm}$ excitation filters was performed by a Sutter DG-4 optical filter changer (Sutter Instrument Company, Novato, CA). Emission light was measured at $510 \mathrm{~nm}$. Data were collected every $4 \mathrm{sec}$ using a SensiCam Digital CCD camera. A Dell Pentium II XPS R400 $\mathrm{MHz}$ computer and Axon Imaging Workbench software were used to control peripheral devices. Digitized, background-subtracted, single-cell ratiometric data from many (up to 100) cells were recorded simultaneously from the same video field.

Fura-2 data were calibrated using a commercially available kit (Molecular Probes fura-2 Calcium Imaging Calibration Kit; F-6774). Solutions containing $50 \mu \mathrm{M}$ fura-2, $100 \mathrm{mM} \mathrm{KCl}, 10 \mathrm{~mm}$ MOPS, and defined $\mathrm{Ca}^{2+}$ concentrations ranging from 0 to $39 \mu \mathrm{M}$ were placed between two glass coverslips and imaged. Ratios for zero $\mathrm{Ca}^{2+}\left(R_{\min }\right)$ and saturating $\mathrm{Ca}^{2+}\left(R_{\max }\right)$ were determined after background fluorescence from a fura-2-free solution had been subtracted. The values of $R_{\min }$ and $R_{\max }$ were substituted into Equation 5 of Grynkiewicz et al. (1985), along with the value $S f / S b$ (zero calcium fluorescence at $380 \mathrm{~nm}$ divided by saturating calcium fluorescence at $380 \mathrm{~nm}$ ) and the dissociation constant of fura-2 $\left(K_{\mathrm{d}}=224 \mathrm{nM}\right)$. Calibrated $\mathrm{Ca}^{2+}$ data were transferred to a Power Macintosh G3 computer and analyzed with Igor Pro and InStat software.

Only $\mathrm{Ca}^{2+}$ changes in cell bodies were recorded. Previous $\mathrm{Ca}^{2+}$ imaging experiments revealed that all cultured hypothalamic neurons are NMDA sensitive (Obrietan and Van den Pol, 1995). Therefore, in our experiments, neurons were recognized by their responsiveness to the application of $10 \mu \mathrm{M}$ NMDA in a $\mathrm{Mg}^{2+}$-free solution and by their "phase-bright" appearance. The responsiveness of chronically blocked neurons to NMDA was also used in some experiments to confirm that cells were healthy and responsive. A neuron was considered as responding to a pharmacological agent (e.g., bicuculline, nicotine, muscarine, NMDA, etc.) if, during the agent application, $\mathrm{Ca}^{2+}$ increased by $>10 \mathrm{nM}$ from the initial background level and if the level of $\mathrm{Ca}^{2+}$ decreased to the background after the agent washout. If $\mathrm{Ca}^{2+}$ oscillations were triggered by the agent, the amplitude of $\mathrm{Ca}^{2+}$ increase was measured at peaks of oscillations.

Northern blots. Total RNA was extracted from cultures, and Northern analysis was performed for three nicotinic ACh receptor (nAChR) subunits $(\alpha 4, \alpha 7, \beta 2)$ and five muscarinic ACh receptors (mAChRs) (m1-m5) as described (O'Hara et al., 1999). Briefly, RNA was extracted using Trizol (BRL) reagent, fractionated on $1.2 \%$ formaldehyde/agarose gels, and transferred to Nytran membranes (Schleicher \& Schuell). RNA was visualized by ethidium bromide staining and cross-linked by UV irradiation. After prehybridization, membranes were hybridized at $42^{\circ} \mathrm{C}$ in $5 \times$ SSC, $50 \%$ formamide, $50 \mathrm{~mm}$ sodium phosphate, $\mathrm{pH} 6.8,1 \%$ SDS, $1 \mathrm{~mm}$ EDTA, $2.5 \times$ Denhardt's, $200 \mathrm{mg} / \mathrm{ml}$ herring sperm DNA, and $1 \times$ $10^{7} \mathrm{cpm} / \mathrm{ml}$ of radiolabeled random-primed cDNA probe. Membranes were washed twice for $30 \mathrm{~min}$ at $58^{\circ} \mathrm{C}$ in $0.4 \times \mathrm{SSC}$ and $0.5 \%$ SDS. Filters were then exposed to Kodak XAR5 film for 1-10 d. Quantitation/ densitometry of the relevant bands corresponding to mRNA hybridization was obtained using a computer-assisted image analysis system MCID (Imaging Research, St. Catherines, Ontario, Canada). Filters were stripped and reprobed sequentially with each AChR cDNA. Each subsequent probing and resultant autoradiogram were carefully analyzed to determine whether any residual radioactivity or banding patterns were evident. All banding patterns were consistent with the previous work (O’Hara et al., 1999). A dilution series was used for comparison to assure that quantitation of autoradiograms was within the linear range for each film exposure. cDNAs for nAChR subunits were obtained from Dr. J. Patrick (Baylor University), and muscarinic cDNAs were obtained from Dr. Tom Bonner (National Institute of Mental Health). Approximately one million cells were used from coverslips to collect $\sim 3 \mu \mathrm{g}$ of total RNA per sample. Units were normalized for each probing. $\beta$-actin mRNA levels were similar across conditions and served as the control.

Toxicity assay. Glutamate and ACh excitotoxicity were estimated using a LIVE/DEAD Kit (Molecular Probes). Cultures were stained for 30 min with calcein AM $(1 \mu \mathrm{M})$, which labels only live cells, and ethidium homodimer-1 $(2 \mu \mathrm{M})$, which labels only dead cells. The coverslips were then washed and exposed to the appropriate excitation wavelengths: 490 $\mathrm{nm}$ (FITC filter) for the analysis of living cells and $580 \mathrm{~nm}$ (Texas Red filter) for the analysis of dead cells. A Nikon inverted microscope with a Nikon Super Fluor $20 \times$ objective was used for the staining analysis. The 


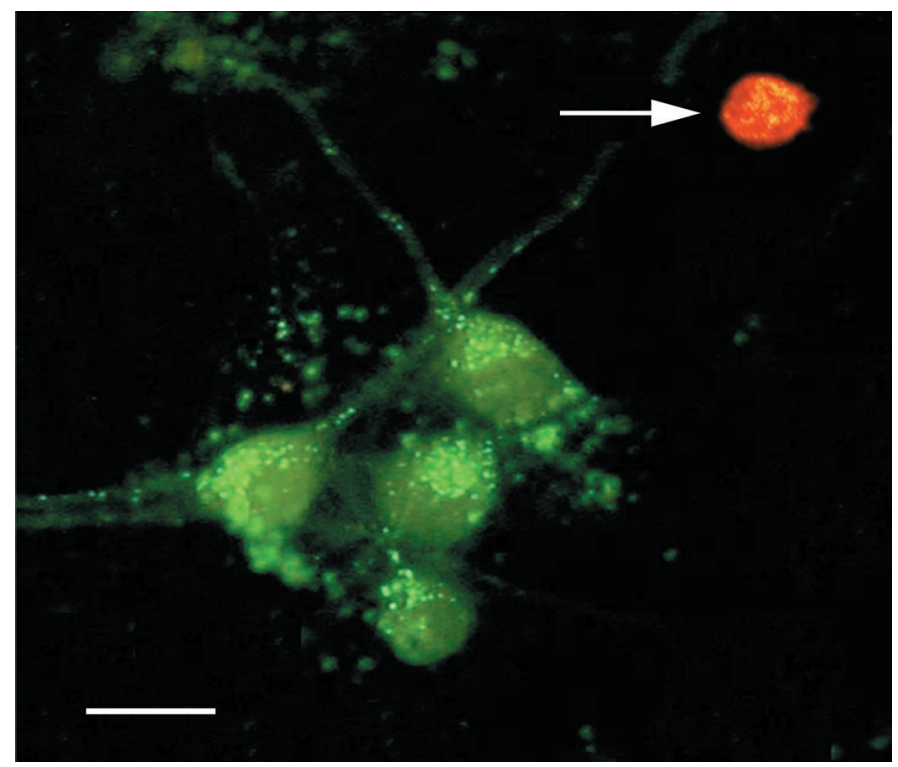

Figure 1. Staining of live and dead cells in hypothalamic neuronal cultures. The picture contains two superimposed images that were taken from the same microscope field using two different filters. The fluorescent colors of live ( green) and dead (red) cells did not overlap. Live neurons were also recognized by the characteristic round or oval cell body and processes. An arrow points at the dead cell. Scale bar, $20 \mu \mathrm{m}$.

fluorescent colors of living ( green) and dead (red) cells did not overlap (Fig. 1). The number of live neurons was counted in 36 randomly chosen fields in three coverslips for each test.

Drugs and chemicals. AP5, CNQX, NMDA, cytosine $\beta$-Darabinof uranoside, tetrodotoxin (TTX), bicuculline methiodide, picrotoxin, atropine sulfate, mecamylamine, nicotine, muscarine, pirenzepine dihydrochloride, $\alpha$-bungarotoxin, $\quad 4$-[[4-formyl-5-hydroxy-6-methyl-3[(phosphonooxy)methyl]-2-pyridinyl]azo]-1,3-benzenedisulfonic acid (PPADS), suramin, propranolol, carbamylcholine chloride (carbachol), and chemicals used for the internal and perfusion solutions (e.g., HEPES, EGTA, Na-ATP, Na-GTP, etc.) were obtained from SigmaRBI. ( \pm )-3-(2-Carboxypiperazin-4-yl)propanephosphonic acid (CPP), $(R S)$-1-aminoindan-1,5-dicarboxylic acid/UPF 523 (AIDA), (2S)- $\alpha$ ethylglutamic acid (EGLU), and ( $R S)$ - $\alpha$-methyl-4-sulfonophenylglycine (MSPG) were obtained from Tocris (Ballwin, MO).

Data analysis. In electrophysiological and $\mathrm{Ca}^{2+}$ experiments, characteristics of all neuronal responses (e.g., amplitude, frequency, etc.) to pharmacological agents were measured between 45 and $60 \mathrm{sec}$ after the beginning of agent application. Statistical analysis of the experimental data was performed using a Power Macintosh G3 computer and InStat software. Data in all experiments were compared by Student's $t$ test, using paired data when possible. All data are reported as mean \pm SEM for the number of neurons indicated.

\section{RESULTS}

\section{Neuronal activity in control hypothalamic cultures}

High-frequency spontaneous EPSPs were detected in currentclamp recordings from 24 of 25 neurons (96\%) in hypothalamic cultures (18-21 DIV). All EPSPs were suppressed by the joint application of ionotropic glutamate receptor antagonists AP5 $(100 \mu \mathrm{M})$ and CNQX $(10 \mu \mathrm{M})(n=24$ of 24 cells) (Figs. $2 a, 3 a)$ and were glutamatergic. EPSPs were not affected by mAChR antagonist atropine and $\mathrm{nAChR}$ antagonist mecamylamine (100 $\mu \mathrm{M}$ each; $n=5$ neurons tested) (Fig. $3 a$ ). The excitatory activity was potentiated by the synaptic disinhibition with the $\mathrm{GABA}_{\mathrm{A}}$ receptor antagonist bicuculline $(50 \mu \mathrm{M})$ (Fig. $3 a)$. The frequency of action potentials was $0.5 \pm 0.2$ spikes/sec before and $4.8 \pm 0.6$ spikes/sec after the application of bicuculline $(n=5 ; p<0.001)$. In three of five cells, bicuculline elicited a depolarization of the

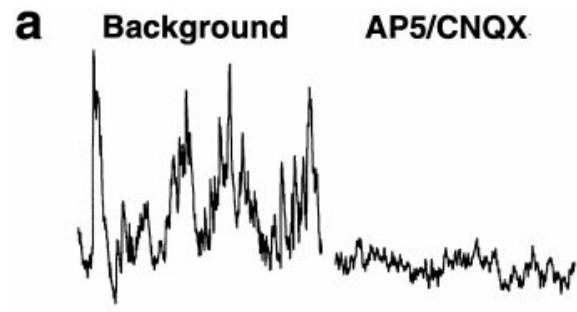

b

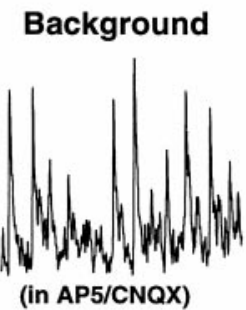

C Background

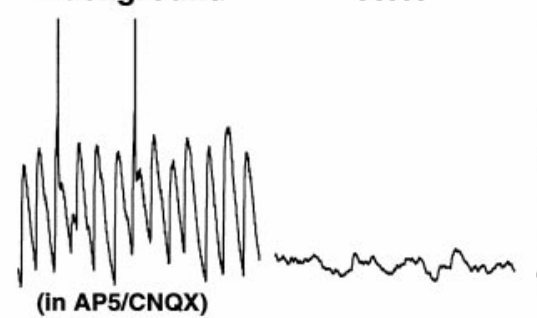

d

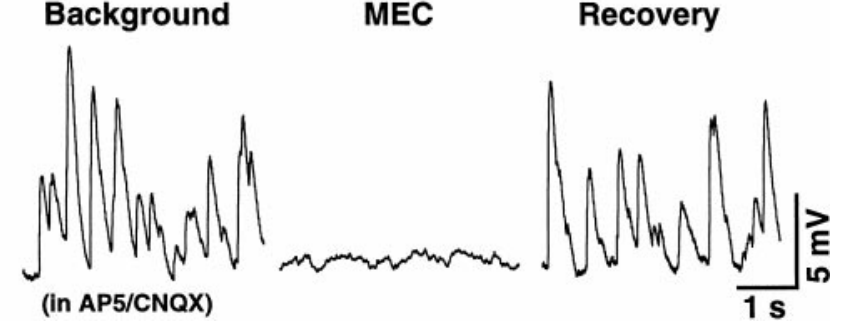

Figure 2. Spontaneous neuronal activity in the control cultures and cultures subjected to a chronic glutamate receptor blockade. Representative current-clamp $(a, c, d)$ and voltage-clamp $(b)$ recordings from two control $(a, b)$ and two blocked $(c, d)$ cells are shown. $a$, Glutamatemediated activity recorded in this control neuron was suppressed with glutamate receptor antagonists $(A P 5 / C N Q X, 100$ and $10 \mu \mathrm{M})$ and recovered after washout. $b$, GABA-mediated activity in another control cell was suppressed with bicuculline $(B I C, 50 \mu \mathrm{M}) . c, d$, ACh-dependent activity recorded in these two chronically blocked neurons was suppressed with either atropine $(c, A T R, 10 \mu \mathrm{M})$ or mecamylamine $(d, M E C, 10 \mu \mathrm{M})$. The following applies in all figures: Background, recording made before the applications of antagonist(s); Recovery, recording made after the antagonist(s) washout. AP5 $(100 \mu \mathrm{M})$ and CNQX $(10 \mu \mathrm{M})$ were in all mediums in $b-d$. Calibration bars: $1 \mathrm{sec}$ (horizontal; $a-d), 5 \mathrm{mV}$ (vertical; $a, c, d), 30 \mathrm{pA}($ vertical; $b)$.

membrane potential $\left(V_{\mathrm{m}}\right)$ from $-59.8 \pm 1.4 \mathrm{mV}$ to $-44.3 \pm 3.4$ $\mathrm{mV}(n=3 ; p<0.02)$ (Fig. $3 a)$. In two other cells, bicuculline evoked large-amplitude EPSPs $(15-19 \mathrm{mV}$; 0.18-0.2 Hz) with only small depolarization (2-3 $\mathrm{mV}$ from the initial background level of $-60 \mathrm{mV}$ ) during inter-EPSP intervals (data not shown). No excitatory activity was detected in control hypothalamic neurons during bicuculline application in the presence of glutamate receptor antagonists $(n=19$ cells tested) (Fig. $3 a)$.

$\mathrm{Ca}^{2+}$ imaging experiments revealed spontaneous glutamatemediated intracellular $\mathrm{Ca}^{2+}$ oscillations in 11 of $200(6 \%)$ control 
Figure 3. ACh-mediated electrical activity after a chronic glutamate receptor blockade. Current-clamp recordings are shown. $a$, This control cell revealed glutamate-dependent EPSPs after the removal of $A P 5 / C N Q X(100$ and $10 \mu \mathrm{M})$ from the incubating medium. This activity was not affected by AChR antagonists $(A T R / M E C ; 100 \mu \mathrm{M}$ each) but was potentiated by synaptic disinhibition $(B I C ; 50 \mu \mathrm{M})$. No response to bicuculline was detected in the cell in the presence of glutamate receptor antagonists. $b$, In this chronically blocked neuron, bicuculline revealed the sustained depolarization and increase in activity that was suppressed with atropine $(100 \mu \mathrm{M})$. $c$, Large spontaneous EPSPs induced by bicuculline in another chronically blocked neuron $(c-2)$ were suppressed with atropine $(c-3)$ and recovered after washout $(c-4)$. After bicuculline washout, activity recovered $(c-5)$ to its initial low level $(c-1) . d$, Bicuculline-induced activity in this blocked neuron $(d-1)$ was not affected by atropine $(100 \mu \mathrm{M} ; d-2)$ but was suppressed by mecamylamine $(100 \mu \mathrm{M} ; d-3)$ or TTX $(1 \mu \mathrm{M} ; d-4)$ and recovered after washout $(d-5)$. Applications of antagonists in $a$ and $b$ are indicated by the bars above the recordings. Dashed lines in $a$ also indicate the time
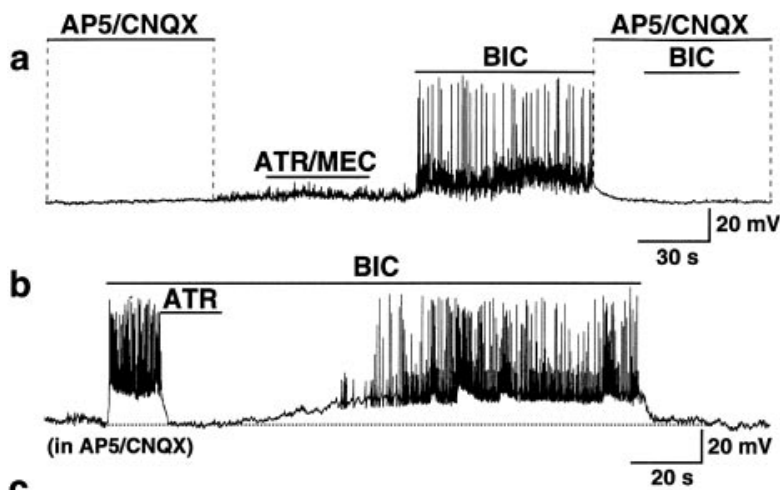

C

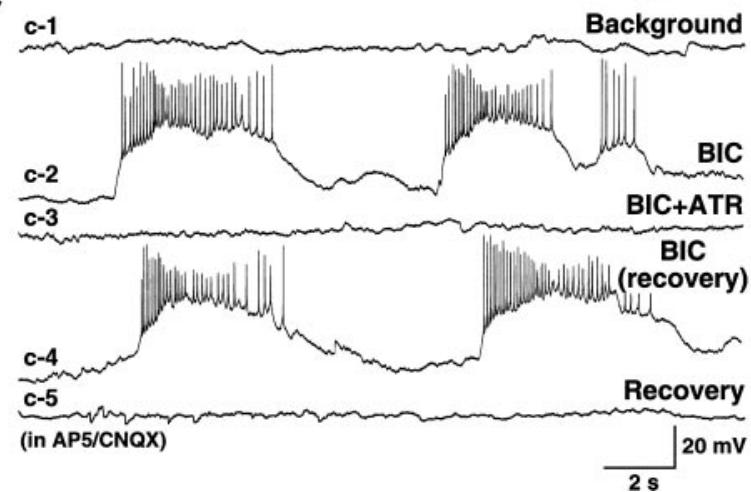

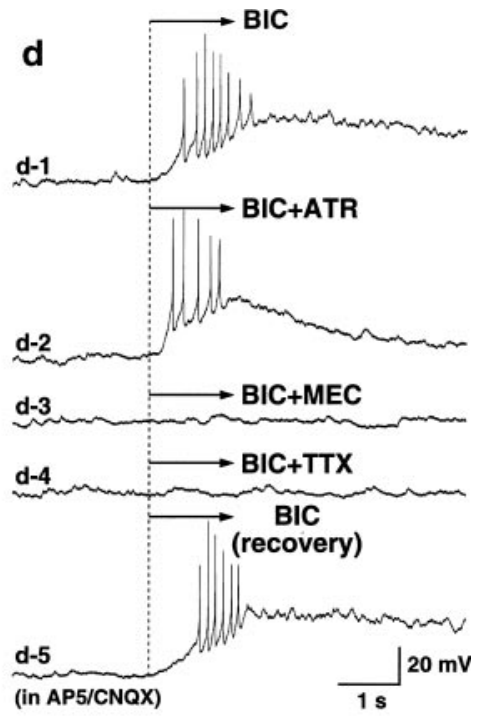

periods of AP5 and CNQX application. The dotted line in $b$ represents the background $V_{\mathrm{m}}$ level. The dashed line in $d$ is the beginning of antagonist(s) application. AP5 $(100 \mu \mathrm{M})$ and CNQX $(10 \mu \mathrm{M})$ were in all solutions in $b-d$. Calibration bars are shown below the recordings.

hypothalamic neurons (Fig. 4a). The frequency of oscillations was $0.051 \pm 0.003 \mathrm{~Hz}(n=11$; range $0.04-0.06 \mathrm{~Hz})$. The average amplitude was $81.5 \pm 10.2 \mathrm{nM} \mathrm{Ca}^{2+}(n=11)$, as measured from the background $\mathrm{Ca}^{2+}$ level that usually was 50-75 nM in different cells. $\mathrm{Ca}^{2+}$ rises were completely suppressed in the presence of glutamate receptor antagonists (AP5 and CNQX, 100 and $10 \mu \mathrm{M}$, respectively; $n=11$ ). They were not affected, however, by atropine and mecamylamine (100 $\mu \mathrm{M}$ each) (Fig. $4 a)$. After the joint application of AChR antagonists, the frequency of $\mathrm{Ca}^{2+}$ oscillations was $0.052 \pm 0.003 \mathrm{~Hz}$ and the amplitude was $92.4 \pm 12.6 \mathrm{nM}$ $\mathrm{Ca}^{2+}$ ( $n=11$; no significant difference from the control). The level of intracellular $\mathrm{Ca}^{2+}$ increased dramatically in almost all tested neurons ( $n=196$ of 200; 98\%) in the presence of bicuculline $(50 \mu \mathrm{M})$ (Fig. $4 a)$. In these cells, the $\mathrm{Ca}^{2+}$ increase was $194.2 \pm 5.9 \mathrm{~nm}$ from the initial background level. Oscillations of intracellular $\mathrm{Ca}^{2+}$, synchronous between many cells, were common in these conditions. Because the bicuculline-mediated $\mathrm{Ca}^{2+}$ increases were not detected in the presence of glutamate receptor antagonists (Fig. 4a) ( $n=436$ cells tested), they likely represented the disinhibition of glutamate excitatory activity in cultured neurons.

Inhibitory neuronal activity was also detected in the control hypothalamic cultures. Voltage-clamp recordings revealed spontaneous IPSCs in 12 of 20 neurons $(60 \%)$ that were completely suppressed by bicuculline $(50 \mu \mathrm{M})$ and therefore were GABA mediated (Fig. 2b) (AP5 and CNQX were in all solutions; holding potential was $-30 \mathrm{mV})$. IPSCs $(n=5$ cells $)$ and also EPSPs $(n=$ 4 cells) were completely and reversibly suppressed by the voltagegated $\mathrm{Na}^{+}$current blocker TTX (1 $\mu \mathrm{M}$; data not shown). These data suggested that virtually all excitation and inhibition in the control hypothalamic cultures were caused by the synaptic release of glutamate and GABA from cultured neurons and activation of ionotropic glutamate and GABA receptors. The data also sup- ported the idea that glutamate and GABA are two major fast neurotransmitters in the hypothalamus (van den Pol et al., 1990).

\section{Upregulation of ACh transmission in hypothalamic cultures after a chronic glutamate receptor blockade}

Chronic (14-17 d) glutamate receptor blockade with AP5 (100 $\mu \mathrm{M})$ and CNQX $(10 \mu \mathrm{M})$ was maintained in some hypothalamic cultures starting 4 DIV ("blocked cultures"). Cultures of the same age (18-21 DIV) not subjected to a glutamate receptor blockade served as control. When characteristics of neuronal activity were measured and compared between blocked and control cultures, no significant difference was detected in the following variables: $V_{\mathrm{m}}$ was $-60.1 \pm 1.9 \mathrm{mV}(n=20)$ in the control and $-59.4 \pm 0.6$ $\mathrm{mV}(n=84)$ in blocked cultures; $R_{\text {input }}$ was $1280 \pm 167 \mathrm{M} \Omega(n=$ $20)$ and $1027 \pm 75 \mathrm{M} \Omega(n=84)$ in the control and after a chronic blockade, respectively; background levels of intracellular $\mathrm{Ca}^{2+}$ were usually between 50 and $75 \mathrm{~nm}(n>2000$; half in each group); as in controls, many chronically blocked neurons $(68 \%$; $n=19$ of 28) expressed spontaneous GABA-mediated IPSCs [in these experiments, IPSCs were recorded in all cells in the presence of AP5 and CNQX; other characteristics of neuronal activity $\left(V_{\mathrm{m}}, R_{\text {input }}\right.$, levels of intracellular $\left.\mathrm{Ca}^{2+}\right)$ were measured with (blocked cultures) or without (control cultures) AP5/CNQX in the incubating medium].

Surprisingly, however, compared with the control cultures in which all excitatory activity was suppressed in the presence of AP5/CNQX (see above), recordings revealed low-amplitude (3-10 mV) spontaneous EPSPs at a frequency of $0.5-5 \mathrm{~Hz}$ in $54 \%$ of blocked neurons ( $n=45$ of 84 ) (Fig. $2 c, d)$. The EPSPs were completely and reversibly suppressed by the $\mathrm{mAChR}$ antagonist atropine $(10-100 \mu \mathrm{M})$ in 8 of 10 neurons (Fig. $2 c$ ) or by the nAChR antagonist mecamylamine $(10 \mu \mathrm{M})$ in 2 of 10 cells (Fig. $2 d$ ). This suggested that they were cholinergic in nature. Addi- 


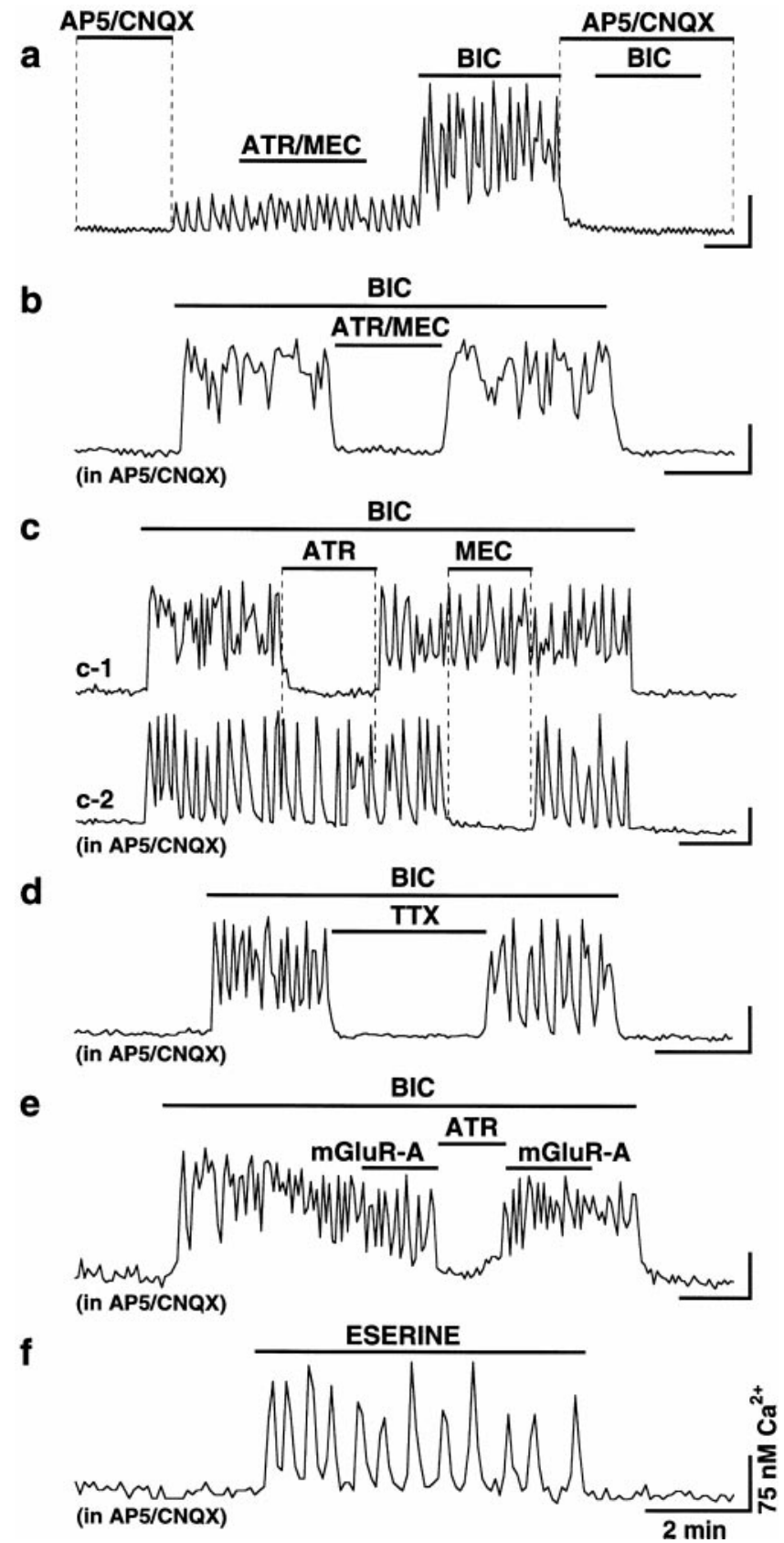

Figure 4. ACh-mediated $\mathrm{Ca}^{2+}$ activity in hypothalamic cultures after a chronic glutamate receptor blockade. $\mathrm{Ca}^{2+}$ digital imaging data obtained from one control $(a)$ and six chronically blocked $(b-f)$ neurons are presented. $a$, Typical control cell revealed glutamate-dependent $\mathrm{Ca}^{2+}$ rises after the removal of $A P 5 / C N Q X(100$ and $10 \mu \mathrm{M})$ from the incubating medium. This activity was not affected by AChR antagonists $(A T R /$ $M E C ; 100 \mu \mathrm{M}$ each) but was potentiated by synaptic disinhibition $(B I C ; 50$ $\mu \mathrm{M})$. No response to bicuculline was detected in the cell in the presence of glutamate receptor antagonists. $b$, In this blocked neuron, bicuculline increased the level of intracellular $\mathrm{Ca}^{2+}$ that was suppressed by atropine and mecamylamine (ATR/MEC; $10 \mu \mathrm{M}$ each) applied jointly. $c$, Two cells in one culture responding differently to the separate application of atropine and mecamylamine (100 $\mu \mathrm{M}$ each). $d, \mathrm{Ca}^{2+}$ activity was blocked with TTX $(1 \mu \mathrm{M}) . e$, The activity was not affected by metabotropic glutamate receptor antagonists ( $m G l u R-A$; see Results for details; $A T R ; 10 \mu \mathrm{M}) . f$, $\mathrm{Ca}^{2+}$ activity was also induced by eserine $(10 \mu \mathrm{M})$. AP5 and CNQX were in all solutions in $b-f$. Bicuculline $(1 \mu \mathrm{M})$ was also in all solutions in $f$. Calibration bars: $2 \mathrm{~min}$ (horizontal) and $75 \mathrm{nM} \mathrm{Ca}^{2+}$ (vertical) for all recordings. tionally, although no excitatory electrical activity was seen in control cultures after synaptic inhibition was blocked with bicuculline $(50 \mu \mathrm{M})$ when AP5 and CNQX were present in the medium $(n=19)$ (Fig. $3 a)$, large amplitude EPSPs, sustained depolarization, and a dramatic increase in action potentials were detected after synaptic disinhibition in 29 of 32 chronically blocked neurons (Fig. 3b-d). The frequency of action potentials was $0.3 \pm 0.1$ and $3.9 \pm 0.5$ spikes/sec before and after the application of bicuculline, respectively $(n=29 ; p<0.0001)$. In the presence of bicuculline, spontaneous large EPSPs $(16-30 \mathrm{mV}$; $0.2-0.25 \mathrm{~Hz}$ ) were found in 17 of $29(59 \%)$ of neurons (Fig. 3c). The rest of the cells (41\%) revealed a sustained depolarization of $V_{\mathrm{m}}$ from the background level of $-59.9 \pm 0.8 \mathrm{mV}$ to $-47.7 \pm 1.1$ $\mathrm{mV}$ after bicuculline application $(n=12 ; p<0.0001)$ (Fig. $3 b)$. The bicuculline-induced epileptiform-like hyperactivity in chronically blocked cultures was suppressed either by atropine (10-100 $\mu \mathrm{M} ; n=7$ of 8 ) (Fig. $3 b, c)$ or by mecamylamine (100 $\mu \mathrm{M} ; n=1$ of 8 ) (Fig. $3 d$ ), suggesting that it was cholinergic in nature.

The bicuculline-induced electrical activity in blocked neurons was associated with a dramatic increase in the level of intracellular $\mathrm{Ca}^{2+}$ (Fig. 4b-e), which was not detected in control neurons in the AP5/CNQX-containing medium (Fig. 4a). In chronically blocked cultures, bicuculline increased intracellular $\mathrm{Ca}^{2+}$ level in 1938 of 2335 neurons (83\%). The amplitude of $\mathrm{Ca}^{2+}$ increase was in the range of $24-770 \mathrm{~nm}$ (average $203.2 \pm 2.0 \mathrm{nM} ; n=1938$ ) as measured relative to the initial background $\mathrm{Ca}^{2+}$ level. During bicuculline application, many of these neurons (52\% of 1938) revealed $\mathrm{Ca}^{2+}$ oscillations that were usually regular and synchronized between all cells in the microscope field and were in the range of $0.02-0.06 \mathrm{~Hz}$ (Fig. 5). $\mathrm{Ca}^{2+}$ increase in other cells $(48 \%$ of 1938) was steady, as shown in Figure $4 b$. The bicucullineinduced $\mathrm{Ca}^{2+}$ activity was blocked or significantly $(>50 \%)$ suppressed with the joint application of atropine and mecamylamine in $67 \%$ of 235 neurons at concentrations of $10 \mu \mathrm{M}$ and in $94 \%$ of 161 neurons at concentrations of $100 \mu \mathrm{M}$ (Fig. 4b, Table 1). Atropine alone blocked or reduced the $\mathrm{Ca}^{2+}$ activity in $39 \%$ (of $144 ; 10 \mu \mathrm{M}$ ) and $69 \%$ (of 269; $100 \mu \mathrm{M}$ ) of neurons, and mecamylamine alone did that in $24 \%$ (of 90; $10 \mu \mathrm{M}$ ) and $48 \%$ (of $65 ; 100 \mu \mathrm{M})$ of cells. When atropine $(100 \mu \mathrm{M})$ and mecamylamine $(100 \mu \mathrm{M})$ were separately applied to the same cells, activity in 5 of 65 neurons (8\%) was suppressed with mAChR but not nAChR antagonist (Fig. $4 c-1$ ), whereas in 3 of 65 cells $(5 \%)$ the effect was the opposite (Fig. 4c-2).

The data described above supported the idea that the bicuculline-induced $\mathrm{Ca}^{2+}$ activity in blocked cultures was of a cholinergic origin. Importantly, the activity was also suppressed by TTX $(1 \mu \mathrm{M})$ in all electrical recordings ( $n=5$ neurons) (Fig. $3 d-4)$ and in most of the $\mathrm{Ca}^{2+}$ imaging experiments (94\% of 228 cells) (Fig. 4d), suggesting the synaptic release of ACh from cultured neurons. The activity was not significantly affected, however, by the antagonists of metabotropic glutamate receptors (AIDA, $100 \mu \mathrm{M}$; EGLU, $100 \mu \mathrm{M}$; and MSPG, $100 \mu \mathrm{M}$; applied together; decrease only in $3 \%$ of 303 cells) (Fig. 4e), P2 purinoreceptors (suramin, $100 \mu \mathrm{M}$; and PPADS, $100 \mu \mathrm{M}$; 0\% of 122 cells; data not shown), and $\beta$-adrenoreceptors (propranolol, $20 \mu \mathrm{M}$; decrease in $2 \%$ of 98 cells; data not shown). Therefore, the activity was not caused by activation of these receptors.

Eserine $(10 \mu \mathrm{M})$, an inhibitor of acetylcholinesterase (enzyme that hydrolyzes $\mathrm{ACh}$ ), also induced $\mathrm{Ca}^{2+}$ increases in 57 of 106 $(54 \%)$ chronically blocked cells (Fig. $4 f$ ). The average amplitude of $\mathrm{Ca}^{2+}$ increase during eserine application was $121.2 \pm 10.0 \mathrm{nM}$, as measured from the initial background level $(n=57 ; p<$ 


\section{BIC}

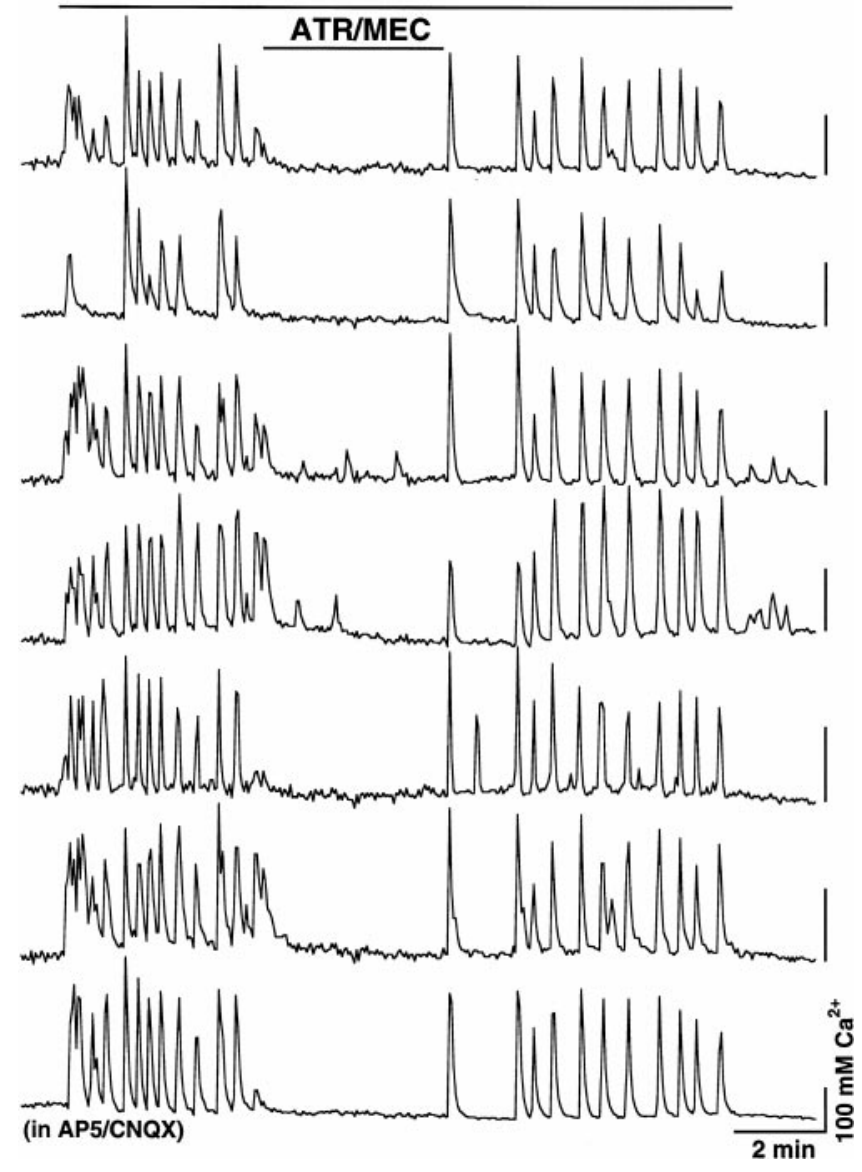

Figure 5. ACh-mediated synchronous intracellular $\mathrm{Ca}^{2+}$ oscillations in blocked hypothalamic neurons. The activity of all seven cells was recorded simultaneously from one microscope field. BIC, $50 \mu \mathrm{M} ; A T R, 10$ $\mu \mathrm{M} ; M E C, 10 \mu \mathrm{M}$. AP5 and CNQX were in all solutions. Calibration bars: 2 min and $100 \mathrm{nM} \mathrm{Ca}^{2+}$ for all recordings.

0.0001 , calculated relative to zero; $1 \mu \mathrm{M}$ bicuculline was in all solutions). In the meantime, in the control cultures, no $\mathrm{Ca}^{2+}$ increase was detected in neurons ( $n=0$ of 132; data not shown) under similar conditions. These data provided further evidence for the upregulation of ACh transmission during a chronic decrease of glutamate excitation.

\section{ACh regulation in cerebellar and cortical cultures}

In our experiments, we also tested the expression of $\mathrm{ACh}$ mediated $\mathrm{Ca}^{2+}$ activity in the control (18 DIV) and chronically blocked (14 DIB/18 DIV) cultures obtained from the cerebellum and cortex. Almost all (98\%; $n=248$ of 253) of the chronically blocked neurons but none $(0 \% ; n=0$ of 211$)$ of the control cerebellar cells increased the level of intracellular $\mathrm{Ca}^{2+}$ (by $\sim 190$ $\mathrm{nM}$ ) or revealed synchronous intracellular $\mathrm{Ca}^{2+}$ oscillations (Fig. $6 a$ ) during the application of bicuculline (AP5 and CNQX were in all mediums). This bicuculline-induced activity was blocked or suppressed $(>50 \%)$ in $81 \%(n=201$ of 248$)$ neurons by the joint application of atropine and mecamylamine (10 $\mu \mathrm{M}$ each) (Fig. $6 a$ ). In cortical cultures, however, bicuculline-induced activity was detected in neither control neurons ( $n=237$ tested) nor neurons after a chronic glutamate receptor blockade $(n=254)$ (Fig. 6b).

\section{Upregulation of $\mathrm{ACh}$ receptors}

Two major types of AChRs have been determined previously in the mammalian CNS, including the hypothalamus: ionotropic
nAChRs (directly coupled to an ionic channel) and metabotropic mAChRs (coupled to GTP-binding proteins) (Seguela et al., 1993; Wei et al., 1994; Shioda et al., 1997). In the CNS, excitatory ACh effects are usually associated with either influx of $\mathrm{Na}^{+}$ and/or $\mathrm{Ca}^{2+}$ into the cell through nAChRs $(\alpha 7 \mathrm{nAChR}$ subunit is especially permeable for $\mathrm{Ca}^{2+}$ ) (Sargent, 1993; Role and Berg, 1996) or with $\mathrm{m} 1$ and $\mathrm{m} 3 \mathrm{mAChR}$-dependent reduction of $\mathrm{K}^{+}$ conductances (Madison et al., 1987; Benson et al., 1988; Vanner et al., 1993); $\mathrm{m} 1$ and $\mathrm{m} 3 \mathrm{mAChRs}$ also increase levels of intracellular $\mathrm{Ca}^{2+}$ through the mobilization of $\mathrm{Ca}^{2+}$ from intracellular stores (McKinney, 1993). We tested whether the increase in ACh transmission in hypothalamic cultures after a chronic glutamate receptor blockade was associated with the upregulation of AChRs. In control cultures, $29(23 \%)$ and $17(13 \%)$ of 128 neurons responded with an increase in intracellular $\mathrm{Ca}^{2+}$ to the application of nicotine and muscarine, respectively (10 $\mu \mathrm{M}$ each) (Fig. $7 a)$. Of 128 cells, $15(12 \%)$ responded only to nicotine, 3 ( $2 \%)$ only to muscarine, $14(11 \%)$ to both agonists, and $96(75 \%)$ to neither of them. Meanwhile, $122(83 \%)$ and $128(87 \%)$ of 147 neurons responded to nicotine and muscarine in blocked cultures (Fig. 7b). Of 147 cells, 19 (13\%) responded only to nicotine, 25 (17\%) responded only to muscarine, $103(70 \%)$ responded to both agonists, and none $(0 \%)$ responded to neither of them. Such selective sensitivity of some neurons to either nicotine or muscarine, as well as selective suppression of bicuculline-mediated activity in some blocked cells by either nAChR or mAChR antagonists (Fig. 4c), may apparently represent the differential expression of two types of AChRs in various hypothalamic neurons. The amplitude of the $\mathrm{Ca}^{2+}$ response to $\mathrm{AChR}$ agonists was also increased in neurons after a chronic glutamate receptor blockade. In blocked neurons compared with the control, $\mathrm{Ca}^{2+}$ response to nicotine was larger by $47 \%$, and response to muscarine was larger by $102 \%$.

The significant upregulation of mRNAs encoding two of five subtypes of mAChRs (Fig. 7c, ml and $m 3$ ) and two of three subunits of nAChRs (Fig. $7 d, \alpha 4$ and $\alpha 7$ ) was also detected in blocked cultures as compared with the control, as determined using Northern blots. When specific antagonists for $\mathrm{m} 1 \mathrm{mAChR}$ (pirenzepine, $5 \mu \mathrm{M}$ ) and $\alpha 7 \mathrm{nAChR}$ ( $\alpha$-bungarotoxin, $100 \mathrm{~nm}$ ) were applied to chronically blocked neurons, they suppressed the bicuculline-induced $\mathrm{Ca}^{2+}$ activity in $48 \%$ of 54 neurons and $38 \%$ of 68 neurons, respectively (Fig. 7e,f, Table 1). This suggested that part of the activity was caused by activation of those AChRs.

\section{Some insights on the mechanisms of glutamate- dependent $\mathrm{ACh}$ regulation}

To further characterize the mechanisms responsible for the development of $\mathrm{ACh}$ activity in hypothalamic cultures during chronic glutamate receptor blockade, we used the partial blockade of NMDA and non-NMDA receptors with $20 \mu \mathrm{M}$ AP5 and 2 $\mu \mathrm{M}$ CNQX for 2 weeks. Although in control cultures such concentrations of AP5 and CNQX were not sufficient to completely block the excitatory effects of externally applied glutamate ( $~ 50 \%$ blockade; $n=78$ cells) (Fig. $8 a$ ), ACh-mediated $\mathrm{Ca}^{2+}$ activity was still detected in $34 \%$ of 80 cells chronically incubated in the presence of $20 \mu \mathrm{M}$ AP5 and $2 \mu \mathrm{M}$ CNQX (Fig. 8b, Table 2). A chronic (14 d) blockade of only NMDA glutamate receptors was sufficient for the upregulation of ACh activity in neurons: $73 \%$ of 90 cells and $69 \%$ of 106 cells expressed ACh-mediated activity in cultures subjected to NMDA receptor antagonists AP5 $(100 \mu \mathrm{M})$ (Fig. $8 c)$ and CPP (5 $\mu \mathrm{M})$ (data not shown), respectively. A blockade of only non-NMDA receptors with $10 \mu \mathrm{M}$ CNQX was 


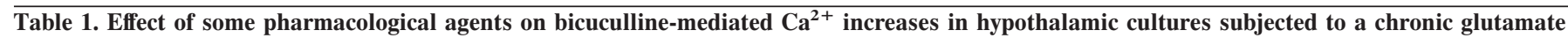
receptor blockade ${ }^{a}$

Number of neurons that decreased bicuculline-mediated response during pharmacological treatment $(\%)$

$n=157$ of $235(67 \%)$

$n=151$ of $161(94 \%)$

$n=56$ of $144(39 \%)$

$n=186$ of $269(69 \%)$

$n=22$ of $90(24 \%)$

$n=31$ of $65(48 \%)$

$n=214$ of $228(94 \%)$

$n=9$ of $303(3 \%)$

$n=0$ of $122(0 \%)$

$n=2$ of $98(2 \%)$

$n=26$ of $54(48 \%)$

$n=26$ of $68(38 \%)$
Bicuculline-mediated $\mathrm{Ca}^{2+}$ response, $n M \mathrm{Ca}^{2+b}$

Before treat
$228.4 \pm 8.3$
$268.7 \pm 7.6$
$153.9 \pm 12.0$
$148.8 \pm 6.4$
$169.6 \pm 8.1$
$191.8 \pm 12.7$
$236.9 \pm 11.3$
$192.2 \pm 18.7$
During treatment

$12.4 \pm 0.8^{* * *}$

$12.3 \pm 1.0^{* * *}$

$19.6 \pm 3.3^{* * *}$

$11.8 \pm 1.1^{* * *}$

$11.2 \pm 1.9^{* * *}$

$13.5 \pm 2.7^{* * *}$

$7.9 \pm 0.9^{* * *}$

$26.7 \pm 11.2^{* * *}$

0

$250.5 \pm 34.5$
$176.5 \pm 9.1$
$185.5 \pm 9.6$

$13.0 \pm 13.0$

$20.8 \pm 3.9^{* * *}$

(n.s.)

$15.1 \pm 2.6^{* * *}$
Treatment

Atropine $(10 \mu \mathrm{M})+$

Mecamilamine $(10 \mu \mathrm{M})$

Atropine $(100 \mu \mathrm{M})+$

Mecamilamine $(100 \mu \mathrm{M})$

Atropine $(10 \mu \mathrm{M})$

Atropine $(100 \mu \mathrm{M})$

Mecamylamine $(10 \mu \mathrm{M})$

Mecamylamine $(100 \mu \mathrm{M})$

TTX $(1 \mu \mathrm{M})$

AIDA $(100 \mu \mathrm{M})+$

EGLU $(100 \mu \mathrm{M})+$

MSPG $(100 \mu \mathrm{M})$

Suramin $(100 \mu \mathrm{M})+$

PPADS $(100 \mu \mathrm{M})$

Propranolol $(20 \mu \mathrm{M})$

Pirenzepine $(5 \mu \mathrm{M})$

$\alpha$-Bungarotoxin (100 nм)

${ }^{a}$ All tests presented here were done in the presence of $100 \mu \mathrm{M}$ AP5 and $10 \mu \mathrm{M}$ CNQX in all media. Bicuculline was $50 \mu \mathrm{M}$.

${ }^{b}$ This column presents the average amplitude of bicuculline-mediated intracellular $\mathrm{Ca}^{2+}$ responses (mean $\pm \mathrm{SEM}$ ) measured before (left) and during (right) the treatment of cells with pharmacological agents that are indicated in the next column. The measurements were done relative to the background $\mathrm{Ca}^{2+}$ level. Calculations of the amplitude are shown only for neurons in which the response was reduced (by $\geq 50 \%$ ) with the subsequent treatment. The number of these neurons is indicated in the first column. Significance of differences (Student's $t$ test): ${ }^{* * *} p<0.0001$; n.s., not significantly different.

not critical for the development of this activity (Fig. 8d) (only $1 \%$ of 233 neurons in such cultures revealed ACh excitation). Elevated potassium $(20 \mathrm{~mm})$, which is known to increase $\mathrm{Ca}^{2+}$ influx to cells through L-type voltage-gated $\mathrm{Ca}^{2+}$ channels (Bessho et al., 1994), could prevent the development of ACh activity in chronically blocked cultures. This was demonstrated in neurons subjected for 2 weeks to $100 \mu \mathrm{M}$ AP5, $10 \mu \mathrm{M}$ CNQX, and $20 \mathrm{~mm}$ $\mathrm{KCl}$, which failed to express ACh-mediated activity $(n=341$ tested) (Fig. 8e). Additionally, no ACh activity was found in neurons chronically $(14 \mathrm{~d})$ incubated in the presence of $1 \mu \mathrm{M}$ TTX, which suppresses neuronal action potentials $(n=109)$ (Fig. $8 f)$. These data suggested that the decrease in $\mathrm{Ca}^{2+}$ influx through NMDA glutamate receptors, rather than activitydependent regulation or inactivation of non-NMDA receptors, may be one mechanism responsible for the increase in ACh transmission during a chronic decrease in glutamate excitation in the hypothalamus in vitro.

We tested the expression of ACh transmission in cultures at different levels of glutamate activity (Fig. $8 g$ ). Cultures in six coverslips were subjected for $14 \mathrm{~d}$ to glutamate receptor blockade with AP5 and CNQX. Two of those six cultures were tested and revealed ACh-mediated $\mathrm{Ca}^{2+}$ rises in $85 \%$ of 169 cells (Fig. $8 g$-2). In the remaining four coverslips, the concentrations of both AP5 $(100 \mu \mathrm{M})$ and CNQX $(10 \mu \mathrm{M})$ in the culture medium were then decreased by $20 \%$ each successive day. After 5 d, AP5 and CNQX were removed completely, and cells were cultured for 10 additional days in the absence of the glutamate receptor antagonists. When cultures in two of those four coverslips were tested, they expressed spontaneous glutamate-mediated EPSPs $(n=3$ cells; data not shown) and did not reveal any ACh-dependent $\mathrm{Ca}^{2+}$ activity $(n=119)$ (Fig. $\left.8 g-3\right)$, as did their sister control cultures that had never been subjected to chronic glutamate receptor blockade (174 cells in two coverslips; 33 DIV) (Fig.
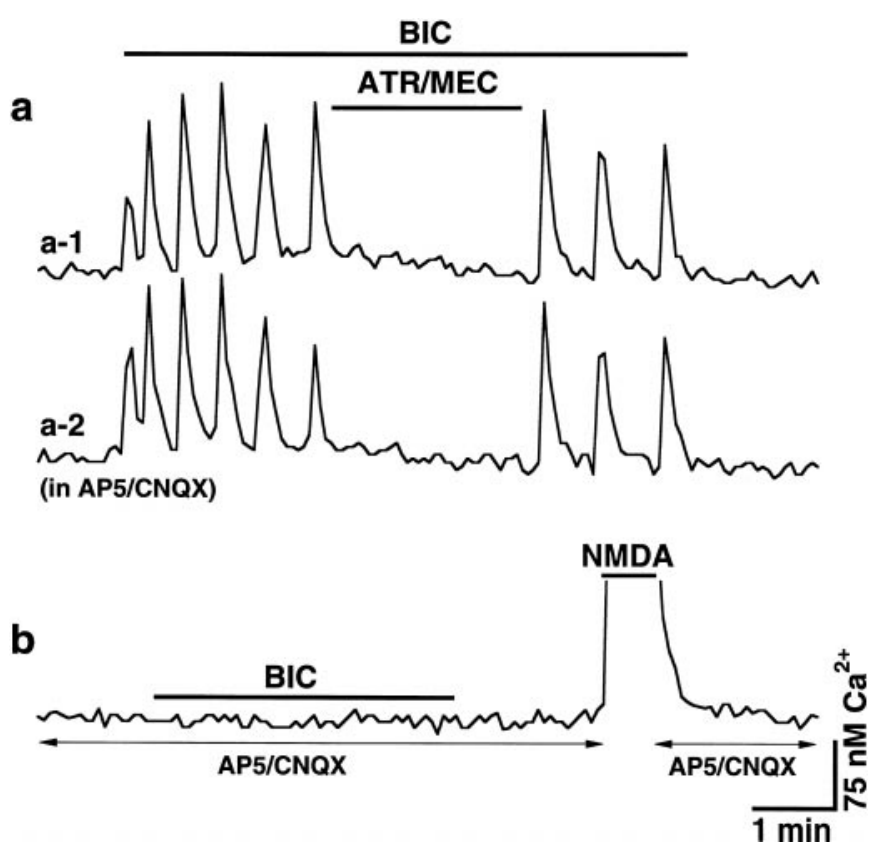

Figure 6. Region-specific character of glutamate-dependent regulation of ACh transmission. $a$, ACh-mediated synchronous $\mathrm{Ca}^{2+}$ oscillations were detected in many cerebellar neurons after a chronic decrease in glutamate excitation. Activity of two representative cerebellar cells in $a$ $(a-1, a-2)$ were recorded simultaneously from the same microscope field. $A T R, 10 \mu \mathrm{M} ; M E C, 10 \mu \mathrm{M}$. $b$, No excitatory activity was detected in chronically blocked cortical neurons. AP5 and CNQX were in all solutions except for the NMDA-containing $(10 \mu \mathrm{M})$ but $\mathrm{Mg}^{2+}$-free solution in $b$ that was used to confirm that the cell was healthy and responsive. Calibration bars: $1 \mathrm{~min}$ and $75 \mathrm{nM} \mathrm{Ca}^{2+}$ for all recordings. 
a

NIC MusC NIC MuSC

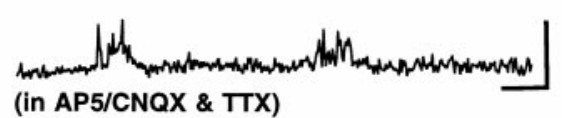

C

Figure 7. Upregulation of AChRs after a chronic glutamate receptor blockade. Data from $\mathrm{Ca}^{2+}$ imaging $(a, b, e, f)$ and Northern blot analyses $(c, d)$ are presented. $a, b$, Responses of two representative control $(a)$ and chronically blocked (b) neurons to nicotine $(N I C ; 10 \mu \mathrm{M})$ and muscarine (MUSC; $10 \mu \mathrm{M}) . c, d$, Expression of mRNAs encoding five mAChRs $(c)$ and three subunits of nAChRs $(d)$ in the control (open bars; $n=4$ coverslips) and chronically blocked ( filled bars; $n=5$ coverslips) cultures. Each bar shows the mean and SE. Significance of differences (Student's $t$ test) relative to the control: ${ }^{*} p<0.05, * * p<0.001,{ }^{* * *} p<0.0001 . e$, $f$, Bicuculline-induced activity in two chronically blocked neurons was suppressed by pirenzepine (e, PIRENZ; 5 $\mu \mathrm{M})$ or $\alpha$-bungarotoxin $(f, \alpha-B U N G ; 100$ nM). AP5 and CNQX were in all solutions in $\mathrm{Ca}^{2+}$ recordings. TTX $(1 \mu \mathrm{M})$ was in all solutions in $a$ and $b$. Calibration bars: 2 min and $75 \mathrm{nM} \mathrm{Ca}^{2+}$ for all $\mathrm{Ca}^{2+}$ recordings.

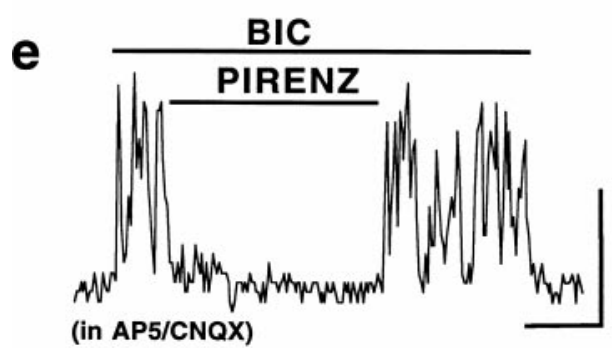

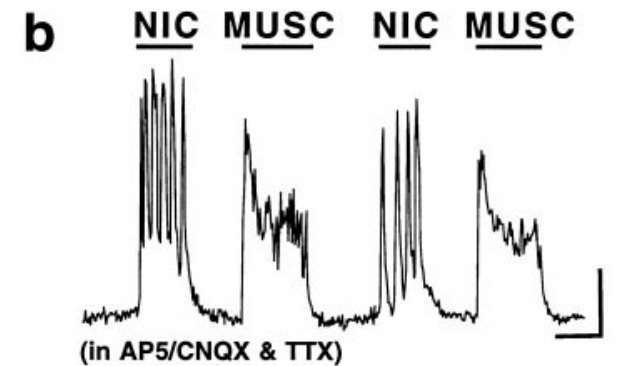
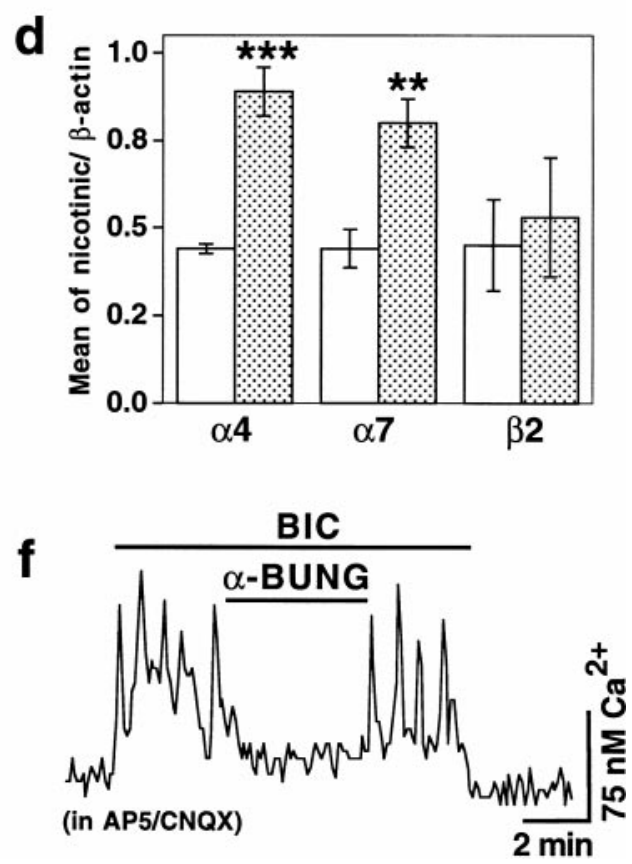

$8 g-1)$. Cultures in the other two of four coverslips were again subjected to a chronic glutamate receptor blockade for the next $10 \mathrm{~d}$. When tested, ACh-mediated $\mathrm{Ca}^{2+}$ activity was detected in these cultures, although in a lower percentage of neurons $(54 \%$ of 105 neurons) (Fig. 8g-4). This showed the dynamic bi-directional plasticity of ACh transmission at different levels of glutamate excitation.

The chronic presence of glutamate receptor antagonists in the incubating medium is known to slow the rate of natural cell death and to increase neuronal survival in cell cultures, which is attributable most likely to a decrease in glutamate excitotoxicity (Obrietan and Van den Pol, 1995). To address the possibility that increased survival of neurons in blocked cultures may be responsible for the increase in ACh excitation, we studied the dynamics of development of ACh activity in blocked cultures. As found previously (Obrietan and Van den Pol, 1995), 10 DIV is the time when the relative number of neurons in the control and chronically blocked hypothalamic cultures is almost identical and the protective effect of glutamate receptor antagonists on neuronal survival is not yet manifested. In our experiments, ACh-mediated activity was already detected in cultures on 10 DIV/6 DIB (12\% of 59 cells) (Fig. 8h). The number of neurons expressing ACh activity quickly increased to $83 \%$ in the following several days (by 14-17 DIB) and did not significantly change after almost 2.5 months of blockade (89\% of 167 cells; 74 DIV/70 DIB) despite the continuous natural cell death. These data suggested that the upregulation of ACh activity was not the result of increased neuronal survival in chronically blocked cultures.
We tested whether ACh excitation can develop in cultures after their maturation or whether only immature cultures develop this activity. In these experiments, hypothalamic cultures were subjected to a chronic $(14 \mathrm{~d})$ glutamate receptor blockade starting at 60 DIV [i.e., well after maturation of synaptic connections in rat hypothalamic cultures (van den Pol et al., 1998)]. Although the ability of cultures to express ACh-mediated activity was reduced, $51 \%$ of 210 tested neurons still revealed ACh excitation (Fig. 8i). These data parallel those from the experiment with the reintroduction of glutamate receptor blockade to 1.5-month-old hypothalamic cultures (see above) (Fig. $8 g-4$ ) and suggest the contribution of both developmental and non-developmental mechanisms to the glutamate-dependent regulation of ACh activity in the hypothalamus in vitro.

\section{ACh supports the excitation/inhibition balance}

A decrease in GABA activity in neuronal cultures or cultured slices obtained from different regions of the CNS can cause an imbalance in synaptic excitation/inhibition and, if sustained, cell death. Application of the $\mathrm{GABA}_{\mathrm{A}}$ receptor antagonists bicuculline $(100 \mu \mathrm{M})$ and picrotoxin $(500 \mu \mathrm{M})$ for $3 \mathrm{~d}$ to cultured hippocampal slices was found previously to cause a glutamatedependent neurodegeneration that could be prevented with the NMDA and non-NMDA receptor antagonists MK-801 and CNQX (Thompson et al., 1996). This supported the idea of the contribution of glutamate and GABA to the regulation of the excitation/inhibition balance in the hippocampus. In our experiments using staining with the Live/Dead Kit, we found that 

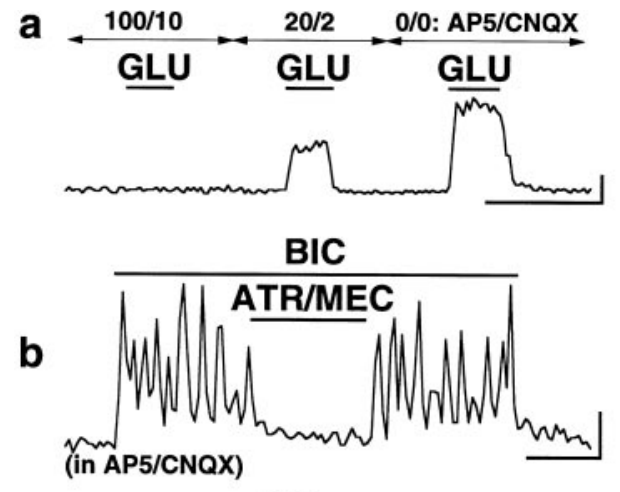

BIC

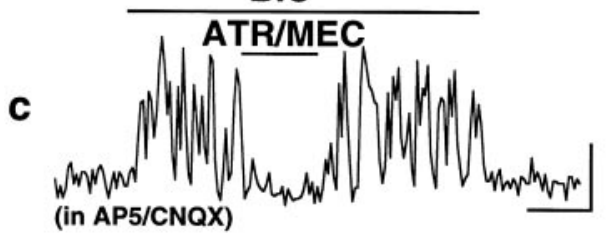

NMDA

d

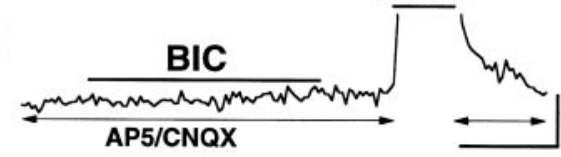

BIC
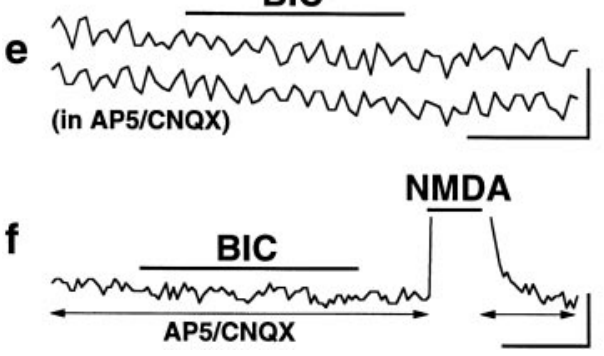

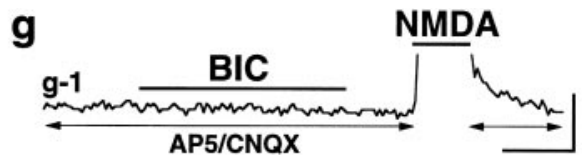

BIC
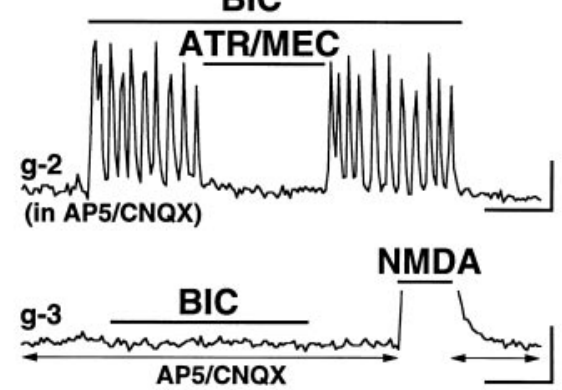

BIC

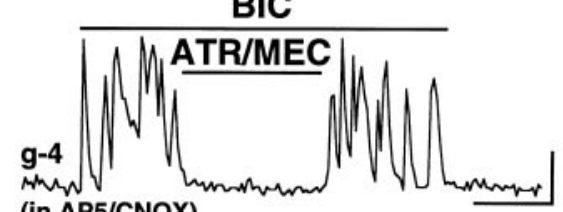

(in AP5/CNQX)

BIC

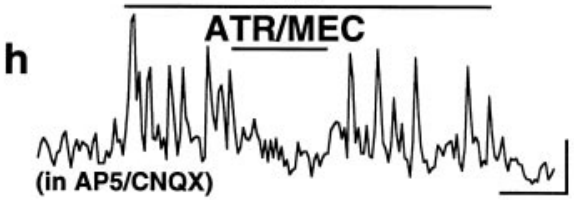

BIC

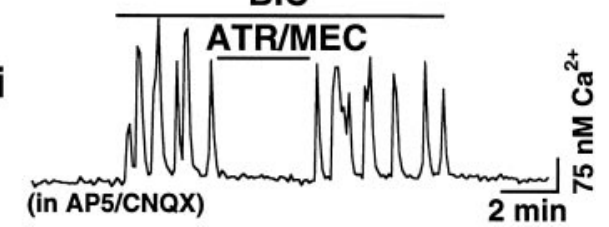

Figure 8. Development of ACh activity in hypothalamic neuronal cultures. Representative recordings from $\mathrm{Ca}^{2+}$ imaging experiments are shown. $a$, Amplitude of responses of control hypothalamic neurons to externally applied glutamate (10 $\mu \mathrm{M})$ was reduced by $\sim 50 \%$ in the presence of $20 \mu \mathrm{M}$ AP5 and $2 \mu \mathrm{M}$ CNQX (20/2). All glutamate-mediated activity recorded in the absence of glutamate receptor antagonists $(0 / 0)$ was suppressed by $100 \mu \mathrm{M}$ AP5 and $10 \mu \mathrm{M}$ CNQX (100/10). Arrows indicate the time of antagonist introduction. $b, \mathrm{ACh}$ activity in culture grown in the presence of $20 \mu \mathrm{M}$ AP5 and $2 \mu \mathrm{M}$ CNQX. $c$, ACh activity in culture grown in the presence of $100 \mu \mathrm{M}$ AP5 alone. $d$, Culture grown in the presence of $10 \mu \mathrm{M}$ CNQX alone. $e$, Neurons grown in the presence of $\mathrm{AP} 5, \mathrm{CNQX}$, and $\mathrm{KCl}(20$ mM) did not reveal ACh activity, but they did express low amplitude (15-20 nM) $\mathrm{Ca}^{2+}$ oscillations synchronized between all cells in the microscope field (two representative cells are shown). $f$, Culture grown in the presence of $1 \mu \mathrm{M}$ TTX. $g$, ACh-mediated $\mathrm{Ca}^{2+}$ activity in cultures at different levels of glutamate excitation (see Results for explanation). $h$, Culture after 10 DIV/6 DIB. $i$, Culture after 74 DIV/14 DIB. All recordings in $b-i$ were done in the presence of AP5 $(100 \mu \mathrm{M})$ and CNQX $(10 \mu \mathrm{M})$ in all solutions. NMDA $(10 \mu \mathrm{M})$ solution in $d, f, g-1$, and $g-3$ did not contain $\mathrm{Mg}^{2+}$, AP5, and CNQX. $b-i$, BIC, $50 \mu \mathrm{M} ; A T R, 100 \mu \mathrm{M} ; M E C, 100 \mu \mathrm{M}$. Calibration bars: 2 min and $75 \mathrm{nM} \mathrm{Ca}^{2+}$ for all recordings. bicuculline and picrotoxin, when applied in the same concentrations to the control hypothalamic cultures for $4 \mathrm{~d}$ (starting 18 DIV), also caused neurodegeneration. The number of live neurons per microscope field (p.m.f.) was $41.3 \pm 2.1$ and $34.1 \pm 1.9$, respectively, in cultures not treated and treated with $\mathrm{GABA}_{\mathrm{A}}$ receptor antagonists as estimated in 36 randomly chosen microscope fields in three coverslips for each test $(p<0.001)$ (Fig. $9 a$, $a-1, a-2)$. The neurodegeneration was prevented with glutamate receptor antagonists AP5 $(100 \mu \mathrm{M})$ and CNQX $(10 \mu \mathrm{M})(42.5 \pm$ 1.8 live cells p.m.f.) (Fig. $9 a, a-3)$, supporting the idea that glutamate and GABA are also involved in the regulation of the excitation/inhibition balance in the hypothalamus in vitro.

We then tested whether after a chronic glutamate receptor blockade ACh supports the excitation/inhibition balance and, namely, whether a prolonged imbalance between ACh excitation and GABA inhibition also leads to cell death. To test this hypothesis, bicuculline $(100 \mu \mathrm{M})$ and picrotoxin $(500 \mu \mathrm{M})$ were added for $4 \mathrm{~d}$ to some chronically blocked hypothalamic cultures starting 18 DIV/14 DIB. Other blocked cultures were not treated with $\mathrm{GABA}_{\mathrm{A}}$ receptor antagonists. In $4 \mathrm{~d}$ (22 DIV/18 DIB), all cultures were stained using the Live/Dead Kit, and the number of live cells was analyzed. In cultures not treated with GABA antagonists, $54.4 \pm 3.8$ live neurons p.m.f. were found (Fig. $9 b$, $b-1)$. Treatment of neurons for $4 \mathrm{~d}$ with bicuculline and picrotoxin significantly decreased the number of live neurons to $19.5 \pm$
3.4 p.m.f. $(p<0.0001)$ (Fig. $9 b, b-2)$. The neurotoxicity mediated by $\mathrm{GABA}_{\mathrm{A}}$ receptor antagonists was prevented with atropine and mecamylamine (100 $\mu$ M each; $61.5 \pm 4.5$ cells p.m.f) (Fig. 9b, $b-3)$, suggesting its cholinergic nature. In another experiment, when the AChR agonist carbachol $(50 \mu \mathrm{M})$ was applied to blocked cultures for $4 \mathrm{~d}$, it decreased the number of live neurons from $52.8 \pm 2.4$ to $17.3 \pm 2.2$ p.m.f. $(p<0.0001)$ (Fig. $9 d, d-1, d-2)$. This was prevented with atropine and mecamylamine $(100 \mu \mathrm{M}$ each; $51.7 \pm 3.5$ p.m.f) (Fig. 9d, $d$-3). Meanwhile, in control cultures (not subjected to a chronic glutamate receptor blockade) no effect of carbachol on cell survival was detected: $44.9 \pm 3.43$, $46.8 \pm 3.09$, and $45.9 \pm 3.0$ live neurons p.m.f. were found in nontreated cultures, carbachol-treated cultures, and cultures treated with carbachol and AChR antagonists, respectively (Fig. 9c).

In these experiments, we also tested cortical cultures subjected to a chronic glutamate receptor blockade. $\mathrm{GABA}_{\mathrm{A}}$ receptor antagonists applied to these cultures for $4 \mathrm{~d}$ did not elicit neurodegeneration. The number of live neurons p.m.f. was $32.2 \pm 2.1$, $33.1 \pm 2.3$, and $34.4 \pm 2.0$ in nontreated cultures, cultures treated with $\mathrm{GABA}_{\mathrm{A}}$ receptor antagonists, and cultures treated with AChR and $\mathrm{GABA}_{\mathrm{A}}$ receptor antagonists, respectively (Fig. 9e). The data suggest that in the absence of glutamate excitatory activity, ACh supports the excitation/inhibition balance in hypothalamic but not cortical cultures. 
Table 2. Acetylcholine-dependent $\mathrm{Ca}^{2+}$ activity in hypothalamic cultures raised under various cell culture conditions ${ }^{a}$

\begin{tabular}{|c|c|c|c|c|}
\hline \multirow[b]{2}{*}{ Culture condition } & \multirow[b]{2}{*}{$\begin{array}{l}\text { Total number of neurons } \\
\text { responding to bicuculline }\end{array}$} & \multirow[b]{2}{*}{$\begin{array}{l}\text { Number of neurons with the } \\
\text { cholinergic response }(\%)^{b}\end{array}$} & \multicolumn{2}{|c|}{$\begin{array}{l}\mathrm{Ca}^{2+} \text { response to bicuculline is re- } \\
\text { duced by } \mathrm{AChR} \text { antagonists, } n M \mathrm{Ca}^{2+}\end{array}$} \\
\hline & & & Bicuculline & $\begin{array}{l}\text { Bicuculline }+ \\
\text { AChR antagonists }\end{array}$ \\
\hline $20 \mu \mathrm{M}$ AP5 $+2 \mu \mathrm{M}$ CNQX & $n=30$ of 80 & $n=27$ of $80(34 \%)$ & $166.9 \pm 9.1$ & $13.3 \pm 2.1 * * * c$ \\
\hline $100 \mu \mathrm{M}$ AP5 & $n=69$ of 90 & $n=66$ of $90(73 \%)$ & $221.2 \pm 13.6$ & $22.4 \pm 2.6^{* * *}$ \\
\hline $5 \mu \mathrm{M} \mathrm{CPP}$ & $n=79$ of 106 & $n=73$ of $106(69 \%)$ & $173.3 \pm 9.5$ & $19.8 \pm 2.3^{* * *}$ \\
\hline $10 \mu \mathrm{M}$ CNQX & $n=2$ of 233 & $n=2$ of $233(1 \%)$ & $156.5 \pm 6.5$ & $14.0 \pm 4.0^{*}$ \\
\hline $100 \mu \mathrm{M}$ AP5 $+10 \mu \mathrm{M}$ CNQX $+20 \mathrm{~mm} \mathrm{KCL}$ & $n=0$ of 341 & $n=0$ of $341(0 \%)$ & 0 & 0 \\
\hline $1 \mu \mathrm{M}$ ТTX & $n=0$ of 109 & $n=0$ of $109(0 \%)$ & 0 & 0 \\
\hline $\mathrm{CONTROL}^{d}$ & $n=0$ of 174 & $n=0$ of $174(0 \%)$ & 0 & 0 \\
\hline $\mathrm{BLOCK}^{e}(18 \mathrm{DIV} / 14 \mathrm{DIB})$ & $n=150$ of 169 & $n=143$ of $169(85 \%)$ & $170.7 \pm 8.1$ & $21.6 \pm 1.6^{* * *}$ \\
\hline $10 \mathrm{~d}$ after BLOCKADE removal & $n=0$ of 119 & $n=0$ of $119(0 \%)$ & 0 & 0 \\
\hline $10 \mathrm{~d}$ after BLOCKADE reintroduction & $n=67$ of 105 & $n=57$ of $105(54 \%)$ & $112.2 \pm 5.2$ & $19.7 \pm 2.8^{* * *}$ \\
\hline BLOCK (10 DIV/6 DIB) & $n=9$ of 59 & $n=7$ of $59(12 \%)$ & $135.4 \pm 18.2$ & $12.8 \pm 5.0^{* *}$ \\
\hline BLOCK (74 DIV/70 DIB) & $n=157$ of 167 & $n=149$ of $167(89 \%)$ & $142.3 \pm 6.2$ & $25.8 \pm 1.9^{* * *}$ \\
\hline BLOCK (74 DIV/14 DIB) & $n=120$ of 210 & $n=107$ of $210(51 \%)$ & $150.1 \pm 5.8$ & $11.9 \pm 1.0^{* * *}$ \\
\hline
\end{tabular}

${ }^{a}$ All cells were tested with bicuculline $(50 \mu \mathrm{M})$ in the presence of $100 \mu \mathrm{M} \mathrm{AP5}$ and $10 \mu \mathrm{M}$ CNQX in the medium.

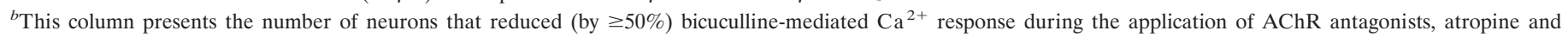

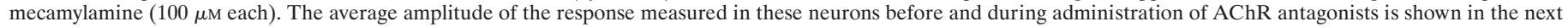
column.

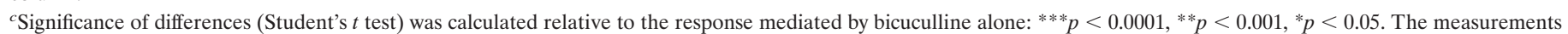
of $\mathrm{Ca}^{2+}$ response were done relative to the initial background $\mathrm{Ca}^{2+}$ level.

${ }^{d}$ CONTROL, Cells from control cultures (33 DIV). The experiment is illustrated in Figure $8 g$.

${ }^{e}$ BLOCK, Cells from cultures chronically incubated in the presence of $100 \mu \mathrm{M}$ AP5 and $10 \mu \mathrm{M}$ CNQX. The time of incubation is shown in parentheses.

\section{DISCUSSION}

Taken together, our experiments demonstrated glutamatedependent bi-directional regulation of cholinergic transmission in cultured neurons: a dramatic increase in excitatory ACh activity and upregulation of AChRs after a chronic blockade of glutamate neurotransmission and a decrease in cholinergic excitation in the presence of glutamate activity. Upregulation of ACh excitation after a decrease in glutamate activity was detected in hypothalamic and cerebellar cultures but not in cultures obtained from the cortex. These data parallel previous observations on rat pups in vivo (Facchinetti et al., 1993, 1994; Virgili et al., 1994, 1998), which also indicated a significant increase in cholinergic function in some regions of the CNS (cerebellum, spinal cord, striatum, globus pallidus, and nucleus accumbens) but not in others (cortex, hippocampus) during a chronic (3 weeks) glutamate receptor blockade. In our in vitro experiments we have determined that a decrease in $\mathrm{Ca}^{2+}$ influx into cells through NMDA glutamate receptors is the principal component responsible for the glutamate-dependent ACh upregulation in neurons. The inactivation of non-NMDA glutamate receptors or the activitydependent mechanisms (inactivation of voltage-gated $\mathrm{Na}^{+}$channels) do not appear to contribute substantially to this upregulation.

Several different factors can cause a decrease in glutamate excitatory transmission in the CNS. Decreased glutamatergic functions in the cortex and striatum have been postulated to be a significant factor in the pathophysiology of schizophrenia (Riederer et al., 1992). Massive death of glutamatergic neurons was established in the human hippocampus during epilepsy (Babb, 1997) and stroke (Mitani et al., 1992; Inglefield et al., 1997), whereas interneurons within this sector continue to survive long term. Although the loss of cholinergic neurons of the basal forebrain was suggested to be responsible for Alzheimer's disease, degeneration of glutamatergic neurons in the hippocampus and cerebral cortex was also implied in the pathogenesis of this disease (Simpson et al., 1988; Lawlor and Davis, 1992). Massive degeneration of the hippocampal and cortical glutamate-secreting projecting neurons may likely reduce glutamate-mediated excitatory synaptic transmission in the brain and deprive target regions of excitatory inputs. Tumors and brain or spinal cord injuries can also damage or destroy glutamate neurons and projections (Llewellyn-Smith et al., 1997). Chronic ethanol exposure may reduce glutamate receptor activity by blocking NMDA receptors (Hoffman et al., 1992). Chronic application of drugs that reduce or completely suppress the activity of ionotropic glutamate receptors is used clinically for the treatment of epilepsy (Rogawski, 1992). Moreover, several clinical trials are currently being performed by National Institutes of Health for a number of NMDA and non-NMDA glutamate receptor antagonists (lamictal, eliprodil, amantadine, dextromethorphan, memantine, topiramate, CGS19755, LY300164, LY293558) for the treatment of Parkinson's disease, Huntington's chorea, orofacial neuralgias, chronic pain, drug dependence, and AIDS dementia (see http://clinicaltrials.gov/). These drugs are used for the chronic treatment of patients: e.g., LY300164 is given three times a day for 3 weeks.

In neuronal circuits, a decrease in glutamate activity usually triggers the compensatory mechanisms that are intended to increase glutamate functions of neurons: upregulation of postsynaptic glutamate receptors, regeneration and sprouting of glutamate terminals, etc. (Follesa and Ticku, 1996; van den Pol et al., 1996; Babb, 1997). Decrease in glutamate excitation may also potentially trigger other compensatory mechanisms, such as reorganization in other neurotransmitter systems, an upregulation of specific neurotrophic factors, an upregulation of certain ionic currents, and a modulation of the second messenger systems and gene expression. In the hypothalamus and some other regions of the CNS, one such compensatory mechanism may include an increase in the expression of $\mathrm{ACh}$, which does not play a signif- 


\section{a. CONTROL CULTURE} (hypothalamus)

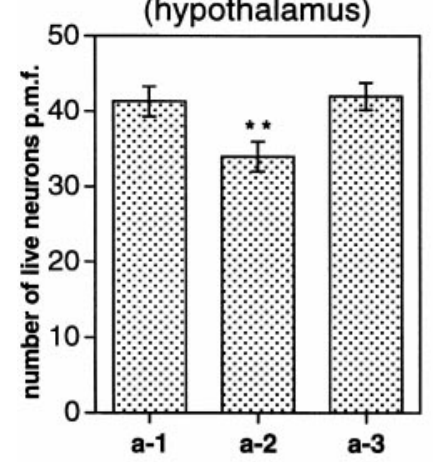

c. CONTROL CULTURE
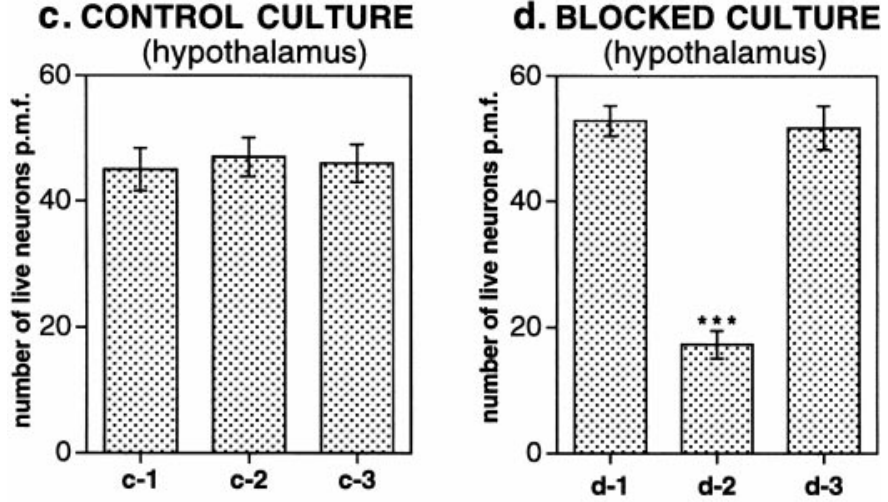

e. BLOCKED CULTURE

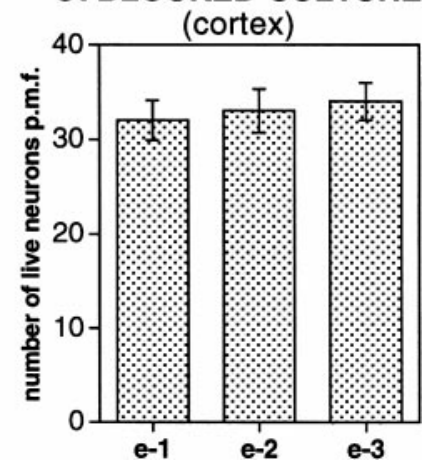

Figure 9. In the absence of glutamate excitation, ACh supports the excitation/inhibition balance in hypothalamic cultures. The number of live neurons per microscope field (p.m.f.) was calculated in control hypothalamic cultures $(a, c)$, in blocked hypothalamic cultures $(b, d)$, and in blocked cortical cultures $(e)$. The first column in all graphs represents no treatment. $a-2, b-2, e-2$, Cultures treated for $4 \mathrm{~d}$ with bicuculline (100 $\mu \mathrm{M})$ and picrotoxin $(500 \mu \mathrm{M}), a-3, b-3, e-3$, Cultures treated for $4 \mathrm{~d}$ with bicuculline $(100 \mu \mathrm{M})$, picrotoxin $(500 \mu \mathrm{M})$, atropine $(100 \mu \mathrm{M})$, and mecamylamine $(100 \mu \mathrm{M}) . c-2, d-2$, Cultures treated for $4 \mathrm{~d}$ with carbachol $(50 \mu \mathrm{M}) . c-3, d-3$, Cultures treated for $4 \mathrm{~d}$ with carbachol $(50 \mu \mathrm{M})$, atropine $(100 \mu \mathrm{M})$, and mecamylamine $(100 \mu \mathrm{M})$. All control cultures were stained on 22 DIV; blocked cultures were stained on 22 DIV/18 DIB. Significance of differences relative to the corresponding group of cells that were not treated: ${ }^{* * *} p<0.0001,{ }^{* *} p<0.001$.

icant role as an excitatory neurotransmitter in the presence of glutamate excitation but begins to play this role when glutamate activity is decreased. In general, the upregulation of ACh transmission may represent the establishment of new pathways in neuronal circuits that allow neurons to continue excitatory communication even with the reduced or absent glutamate activity, which is normally responsible for the fast excitatory communica- tion in the CNS. Consistent with this hypothesis are our data revealing neurotoxic effects of both synaptically released ACh and externally applied AChR agonist in blocked but not control hypothalamic cultures, suggesting that in the absence of glutamate, ACh supports the synaptic excitation/inhibition balance. Other observations have also revealed ACh hyperactivity, hypersensitivity, and sprouting of cholinergic projections that accompany the neurodegeneration of glutamate neurons in the hippocampus during epilepsy (Kish et al., 1988; Holtzman and Lowenstein, 1995; Correia et al., 1998). Cholinergic sprouting and ACh hypersensitivity have also been reported previously in the brain of Alzheimer's disease patients even when a minimal loss of cholinergic neurons in the basal forebrain was detected (Geddes et al., 1985). Additionally in our experiments, ACh excitation developed in hypothalamic cultures during the time frame (1-2 weeks) comparable with that of clinical treatment of patients with glutamate receptor antagonists. This suggests a possibility for the upregulation of ACh transmission in the CNS during clinical use of glutamate receptor blocking agents.

It is important to note that neuronal regeneration and development share many mechanisms and regulatory molecules that regulate axonal outgrowth and pathfinding, formation of synaptic connections, trophic interactions between synapses and target cells, and changes in neurotransmitter release and reception (Nicholls et al., 1992; Purves et al., 1997). Therefore, although the upregulation of ACh transmission can be seen as the regeneration of excitatory inputs to neurons aimed to compensate for the decrease in glutamate excitation, this may also represent the developmental aspects of $\mathrm{ACh}$-glutamate interaction. In fact, in our experiments, when hypothalamic cultures were subjected to a chronic glutamate receptor blockade well after their maturation, the number of cells that revealed ACh activity in $\mathrm{Ca}^{2+}$ recordings was reduced in these cultures as compared with young cultures. This suggested the contribution of both developmental and non-developmental mechanisms to glutamate-dependent regulation of ACh transmission. Moreover, ACh appears to be the major excitatory neurotransmitter in the retina (Feller et al., 1996) and spinal cord (Milner and Landmesser, 1999) during early stages of development, before glutamate begins to play this role at the later stages. Indirect evidence also suggests high levels of cholinergic activity in the hypothalamus of rat and mouse on embryonic days 15-18 (Schambra et al., 1989; Naeff et al., 1992; Zoli et al., 1995), whereas glutamate activity in this region is not yet manifested (Chen et al., 1995). Because a chronic blockade of NMDA glutamate receptors leads to the development of a brain with immature network properties, as suggested earlier (Gorter and Brady, 1994; Scheetz et al., 1996), it is possible that such blockade may also preserve (or reestablish) ACh activity in cultures of those CNS regions where ACh excitation is typical at earlier stages of development. If this assumption is true, the expression of ACh activity during a chronic glutamate receptor blockade in retinal and spinal cultures can also be expected to occur.

Importantly, our experiments also revealed the upregulation of excitatory cholinergic neurotransmission even after a partial $(\sim 50 \%)$ decrease in glutamate activity. Such culture conditions are probably more relevant to pathological or developmental conditions in vivo than to a total decrease in glutamate excitation.

Several possible mechanisms may potentially account for the upregulation of ACh transmission after a decrease in glutamate excitation. One possibility is a direct $\mathrm{Ca}^{2+}$-dependent regulation of cholinergic gene expression described previously for excitable 
cells (Walke et al., 1994). A second possibility is an increase in the expression of cholinergic differentiation factors that trigger the switch of neurons from a noncholinergic to a cholinergic phenotype. The presence of such factors in the CNS (e.g., ciliary neurotrophic factor and leukemia inhibitory factor) has been established (Landis, 1990). The ability of these factors to increase the cholinergic properties of cultured neurons was found to be prevented with elevated $\mathrm{K}^{+}$(or increased $\mathrm{Ca}^{2+}$ influx to cells) and was less pronounced in older cultures (Landis, 1990). The development of ACh activity in chronically blocked hypothalamic cultures in our experiments was also prevented under similar depolarizing conditions and was reduced after culture maturation. A third possible mechanism may include sprouting of already existing cholinergic neurons and cholinergic synaptogenesis. The axonal sprouting, elongation of neurites, and increase in spine density have been detected previously during glutamate receptor blockade in tectal cultures (Lin and Constantine-Paton, 1998) and lateral geniculate slices (Rocha and Sur, 1995). In contrast, activation of glutamate receptors suppressed axon extension of cultured cerebellar granular neurons (Baird et al., 1996).

In conclusion, the upregulation of excitatory ACh transmission detected in our experiments on the hypothalamus in vitro appears to represent a novel form of neuronal plasticity that regulates the activity and excitability of neurons and supports the excitation/ inhibition balance in many neuronal circuits in the CNS during a long-term decrease in glutamate excitation.

\section{REFERENCES}

Babb TL (1997) Axonal growth and neosynaptogenesis in human and experimental hippocampal epilepsy. Adv Neurol 72:45-51.

Baird DH, Trenkner E, Mason CA (1996) Arrest of afferent axon extension by target neurons in vitro is regulated by the NMDA receptor. J Neurosci 16:2642-2648.

Belousov AB, van den Pol AN (1997a) Dopamine inhibition: enhancement of GABA activity and potassium channel activation in hypothalamic and arcuate nucleus neurons. J Neurophysiol 78:674-688.

Belousov AB, van den Pol AN (1997b) Local synaptic release of glutamate from neurons in the rat hypothalamic arcuate nucleus. J Physiol (Lond) 499:747-761.

Benson DM, Blitzer RD, Landau EM (1988) An analysis of the depolarization produced in guinea-pig hippocampus by cholinergic receptor stimulation. J Physiol (Lond) 404:479-496.

Bessho Y, Nawa H, Nakanishi S (1994) Selective up-regulation of an NMDA receptor subunit mRNA in cultured cerebellar granule cells by $\mathrm{K}(+)$-induced depolarization and NMDA treatment. Neuron 12:87-95.

Bradford HF (1995) Glutamate, GABA and epilepsy. Prog Neurobiol 47:477-511.

Chen G, Trombley PQ, van den Pol AN (1995) GABA receptors precede glutamate receptors in hypothalamic development; differential regulation by astrocytes. J Neurophysiol 74:1473-1484.

Choi DW (1994) Glutamate receptors and the induction of excitotoxic neuronal death. Prog Brain Res 100:47-51.

Correia L, Amado D, Cavalheiro EA, Bentivoglio M (1998) Persistence and atrophy of septal/diagonal band neurons expressing the p75 neurotrophin receptor in pilocarpine-induced chronic epilepsy in the rat. Brain Res 809:288-293.

Facchinetti F, Ciani E, Dall'Olio R, Virgili M, Contestabile A, Fonnum F (1993) Structural, neurochemical and behavioural consequences of neonatal blockade of NMDA receptor through chronic treatment with CGP 39551 or MK-801. Brain Res Dev Brain Res 74:219-224.

Facchinetti F, Dall'Olio R, Ciani E, Sparapani M, Virgili M, Contestabile A (1994) Long-lasting effects of chronic neonatal blockade of $N$-methyl-D-aspartate receptor through the competitive antagonist CGP 39551 in rats. Neuroscience 60:343-353.

Feller MB, Wellis DP, Stellwagen D, Werblin FS, Shatz CJ (1996) Requirement for cholinergic synaptic transmission in the propagation of spontaneous retinal waves. Science 272:1182-1187.

Follesa P, Ticku MK (1996) NMDA receptor upregulation: molecular studies in cultured mouse cortical neurons after chronic antagonist exposure. J Neurosci 16:2172-2178.

Furshpan EJ, Potter DD (1989) Seizure-like activity and cellular damage in rat hippocampal neurons in cell culture. Neuron 3:199-207.

Geddes JW, Monaghan DT, Cotman CW, Lott IT, Kim RC, Chui HC
(1985) Plasticity of hippocampal circuitry in Alzheimer's disease. Science 230:1179-1181.

Gorter JA, Brady RJ (1994) NMDA receptor responses in adult hippocampal CA1 region after neonatal treatment with MK-801: comparison with NMDA receptor responses in the immature rat. Brain Res 665:63-68.

Hoffman PL, Grant KA, Snell LD, Reinlib L, Iorio K, Tabakoff B (1992) NMDA receptors: role in ethanol withdrawal seizures. Ann NY Acad Sci 654:52-60

Holtzman DM, Lowenstein DH (1995) Selective inhibition of axon outgrowth by antibodies to NGF in a model of temporal lobe epilepsy. J Neurosci 15:7062-7070.

Inglefield JR, Wilson CA, Schwartz-Bloom RD (1997) Effect of transient cerebral ischemia on gamma-aminobutyric acidA receptor alpha 1-subunit-immunoreactive interneurons in the gerbil CA1 hippocampus. Hippocampus 7:511-523.

Kish SJ, Olivier A, Dubeau F, Robitaille Y, Sherwin AL (1988) Increased activity of choline acetyltransferase and acetylcholinesterase in actively epileptic human cerebral cortex. Epilepsy Res 2:227-231.

Landis SC (1990) Target regulation of neurotransmitter phenotype. Trends Neurosci 13:344-350.

Lawlor BA, Davis KL (1992) Does modulation of glutamatergic function represent a viable therapeutic strategy in Alzheimer's disease? Biol Psychiatry 31:337-350.

Lin SY, Constantine-Paton M (1998) Suppression of sprouting: an early function of NMDA receptors in the absence of AMPA/kainate receptor activity. J Neurosci 18:3725-3737.

Llewellyn-Smith IJ, Cassam AK, Krenz NR, Krassioukov AV, Weaver LC (1997) Glutamate- and GABA-immunoreactive synapses on sympathetic preganglionic neurons caudal to a spinal cord transection in rats. Neuroscience 80:1225-1235.

Madison DV, Lancaster B, Nicoll RA (1987) Voltage clamp analysis of cholinergic action in the hippocampus. J Neurosci 7:733-741.

McKinney M (1993) Muscarinic receptor subtype-specific coupling to second messengers in neuronal systems. Prog Brain Res 98:333-340.

Meeker RB, Greenwood RS, Hayward JN (1994) Glutamate receptors in the rat hypothalamus and pituitary. Endocrinology 134:621-629.

Milner LD, Landmesser LT (1999) Cholinergic and GABAergic inputs drive patterned spontaneous motoneuron activity before target contact. J Neurosci 19:3007-3022.

Mitani A, Andou Y, Kataoka K (1992) Selective vulnerability of hippocampal CA1 neurons cannot be explained in terms of an increase in glutamate concentration during ischemia in the gerbil: brain microdialysis study. Neuroscience [Erratum (1992) 50:251] 48:307-313.

Mody I, Otis TS, Staley KJ, Kohr G (1992) The balance between excitation and inhibition in dentate granule cells and its role in epilepsy. Epilepsy Res [Suppl] 9:331-339.

Naeff B, Schlumpf M, Lichtensteiger W (1992) Pre- and postnatal development of high-affinity $\left[{ }^{3} \mathrm{H}\right]$ nicotine binding sites in rat brain regions: an autoradiographic study. Brain Res Dev Brain Res 68:163-174.

Nicholls JG, Martin AR, Wallace BG (1992) Denervation and regeneration of synaptic connections. In: A cellular and molecular approach to the function of the nervous system, pp 388-421. Sunderland, MA: Sinauer.

O'Hara BF, Macdonald E, Clegg D, Wiler SW, Andretic R, Cao VH, Miller JD, Heller HC, Kilduff TS (1999) Developmental changes in nicotinic receptor mRNAs and responses to nicotine in the suprachiasmatic nucleus and other brain regions. Brain Res Mol Brain Res 66:71-82.

Obrietan K, van den Pol AN (1995) Calcium hyperexcitability in neurons cultured with glutamate receptor blockade. J Neurophysiol 73:1524-1536.

Obrietan K, van den Pol AN (1998) GABAB receptor-mediated inhibition of GABAA receptor calcium elevations in developing hypothalamic neurons. J Neurophysiol 79:1360-1370.

Purves D, Augustine GJ, Fitzpatrick D, Katz LC, LaMantia A-S, McNamara JO (1997) Neuroscience. Sunderland, MA: Sinauer.

Riederer P, Lange KW, Kornhuber J, Danielczyk W (1992) Glutamatergic-dopaminergic balance in the brain. Its importance in motor disorders and schizophrenia. Arzneimittelforschung 42:265-268.

Rocha M, Sur M (1995) Rapid acquisition of dendritic spines by visual thalamic neurons after blockade of $N$-methyl-D-aspartate receptors. Proc Natl Acad Sci USA 92:8026-8030.

Rogawski MA (1992) The NMDA receptor, NMDA antagonists and epilepsy therapy. A status report. Drugs 44:279-292.

Role LW, Berg DK (1996) Nicotinic receptors in the development and modulation of CNS synapses. Neuron 16:1077-1085.

Sargent PB (1993) The diversity of neuronal nicotinic acetylcholine receptors. Annu Rev Neurosci 16:403-443.

Schambra UB, Sulik KK, Petrusz P, Lauder JM (1989) Ontogeny of cholinergic neurons in the mouse forebrain. J Comp Neurol 288:101-122.

Scheetz AJ, Prusky GT, Constantine-Paton M (1996) Chronic NMDA receptor antagonism during retinotopic map formation depresses $\mathrm{CaM}$ 
kinase II differentiation in rat superior colliculus. Eur J Neurosci 8:1322-1328.

Seguela P, Wadiche J, Dineley-Miller K, Dani JA, Patrick JW (1993) Molecular cloning, functional properties, and distribution of rat brain alpha 7: a nicotinic cation channel highly permeable to calcium. J Neurosci 13:596-604.

Shioda S, Nakajo S, Hirabayashi T, Nakayama H, Nakaya K, Matsuda K, Nakai Y (1997) Neuronal nicotinic acetylcholine receptor in the hypothalamus: morphological diversity and neuroendocrine regulations. Brain Res Mol Brain Res 49:45-54.

Simpson MD, Royston MC, Deakin JF, Cross AJ, Mann DM, Slater P (1988) Regional changes in $\left[{ }^{3} \mathrm{H}\right] \mathrm{D}$-aspartate and $\left[{ }^{3} \mathrm{H}\right] \mathrm{TCP}$ binding sites in Alzheimer's disease brains. Brain Res 462:76-82.

Thompson SM, Fortunato C, McKinney RA, Muller M, Gahwiler BH (1996) Mechanisms underlying the neuropathological consequences of epileptic activity in the rat hippocampus in vitro. J Comp Neurol 372:515-528.

van den Pol AN, Wuarin JP, Dudek FE (1990) Glutamate, the dominant excitatory transmitter in neuroendocrine regulation. Science 250:1276-1278.

van den Pol A, Hermans-Borgmeyer I, Hofer M, Ghosh P, Heinemann S (1994) Ionotropic glutamate-receptor gene expression in hypothalamus: localization of AMPA, kainate, and NMDA receptor RNA with in situ hybridization. J Comp Neurol 343:428-444.

van den Pol AN, Obrietan K, Belousov A (1996) Glutamate hyperexcitability and seizure-like activity throughout the brain and spinal cord upon relief from chronic glutamate receptor blockade in culture. Neuroscience 74:653-674

van den Pol AN, Obrietan K, Belousov AB, Yang Y, Heller HC (1998) Early synaptogenesis in vitro: role of axon target distance. J Comp Neurol 399:541-560.

Vanner S, Evans RJ, Matsumoto SG, Surprenant A (1993) Potassium currents and their modulation by muscarine and substance $\mathrm{P}$ in neuronal cultures from adult guinea pig celiac ganglia. J Neurophysiol 69:1632-1644.

Virgili M, Facchinetti F, Contestabile A (1994) Chronic neonatal NMDA blockade results in long-term cholinergic increase in the rat spinal cord. NeuroReport 5:2023-2025.

Virgili M, Facchinetti F, Sparapani M, Tregnago M, Lucchi R, Dall'Olio R, Gandolfi O, Contestabile A (1998) Neuronal nitric oxide synthase is permanently decreased in the cerebellum of rats subjected to chronic neonatal blockade of $N$-methyl-D-aspartate receptors. Neurosci Lett 258:1-4.

Walke W, Staple J, Adams L, Gnegy M, Chahine K, Goldman D (1994) Calcium-dependent regulation of rat and chick muscle nicotinic acetylcholine receptor (nAChR) gene expression. J Biol Chem 269:19447-19456.

Wei J, Walton EA, Milici A, Buccafusco JJ (1994) m1-m5 muscarinic receptor distribution in rat CNS by RT-PCR and HPLC. J Neurochem 63:815-821.

Zoli M, Le Novere N, Hill Jr JA, Changeux JP (1995) Developmental regulation of nicotinic $\mathrm{ACh}$ receptor subunit mRNAs in the rat central and peripheral nervous systems. J Neurosci 15:1912-1939. 